\title{
RNase J1 and J2 Are Host-Encoded Factors for Plasmid Replication
}

\author{
Vanessa Andrade Guimarães ${ }^{1}$, Alexandre Le Scornet ${ }^{2}$, Vanessa Khemici' ${ }^{1}$ \\ Stéphane Hausmann', Joshua Armitano', Julien Prados', Ambre Jousselin², \\ Caroline Manzano ${ }^{1}$, Patrick Linder ${ }^{1}$ and Peter Redder ${ }^{1,2 *}$
}

'Department of Microbiology and Molecular Medicine, Faculty of Medicine, University of Geneva, Geneva, Switzerland, ${ }^{2}$ Laboratoire de Microbiologie et Génétique Moléculaires, Centre de Biologie Integrative, Paul Sabatier University, Toulouse, France

Plasmids need to ensure their transmission to both daughter-cells when their host divides, but should at the same time avoid overtaxing their hosts by directing excessive host-resources toward production of plasmid factors. Naturally occurring plasmids have therefore evolved regulatory mechanisms to restrict their copy-number in response to the volume of the cytoplasm. In many plasmid families, copy-number control is mediated by a small plasmid-specified RNA, which is continuously produced and rapidly degraded, to ensure that its concentration is proportional to the current plasmid copynumber. We show here that pSA564 from the RepA_N-family is regulated by a small antisense RNA (RNA1), which, when over-expressed in trans, blocks plasmid replication and cures the bacterial host. The $5^{\prime}$ untranslated region ( $\left.5^{\prime} \cup T R\right)$ of the plasmid replication initiation gene (repA) potentially forms two mutually exclusive secondary structures, ON and OFF, where the latter both sequesters the repA ribosome binding site and acts as a rho-independent transcriptional terminator. Duplex formation between RNA1 and the 5'UTR shifts the equilibrium to favor the putative OFF-structure, enabling a single small RNA to down-regulate repA expression at both transcriptional and translational levels. We further examine which sequence elements on the antisense RNA and on its $5^{\prime}$ UTR target are needed for this regulation. Finally, we identify the host-encoded exoribonucleases RNase $\mathrm{J} 1$ and $\mathrm{J} 2$ as the enzymes responsible for rapidly degrading the replication-inhibiting section of RNA1. This region accumulates and blocks RepA expression in the absence of either RNase $\mathrm{J} 1$ or $\mathrm{J} 2$, which are therefore essential host factors for pSA564 replication in Staphylococcus aureus.

Keywords: Staphylococcus aureus, plasmid replication control, RNase J, antisense RNA, essential host factors

\section{INTRODUCTION}

The bacterium Staphylococcus aureus is a versatile opportunistic pathogen present in the nasal cavities of 20-30\% of the population (Mulcahy and McLoughlin, 2016). In some instances, S. aureus can cause life threatening diseases such as endocarditis, osteomyelitis, or sepsis, and it is well known for the production of several toxins (Lowy, 1998). A major problem of S. aureus infection is the frequent presence of antibiotic resistant strains which are difficult to eradicate. Indeed penicillin resistance had already been reported for S. aureus by the early 1940s (Lobanovska and Pilla, 2017), 
and $S$. aureus has been proven to be a champion in acquiring antibiotic resistances by horizontal gene transfer. This transfer is particularly efficient if the resistance gene is carried on a plasmid, as in the case of $\beta$-lactamases. Many different types of plasmids have been described for $S$. aureus, small and large, low and high copy number, using theta and rolling circle replication mechanisms, conjugative or not (Firth et al., 2018). The RepA_N family plasmids are generally large and replicate via a theta-replication mechanism. They usually encode a marker for penicillin resistance and frequently have acquired additional resistance cassettes as well. Although the RepA_N family is widespread among Firmicutes, each individual plasmid appears to have a quite narrow host range (Weaver et al., 2009).

All plasmids must regulate their copy number in order to limit the burden for the host cell. While several control mechanisms exist, most $S$. aureus plasmids described use an antisense RNAs for controlling replication initiation (Brantl, 2014). For example in pSK1 and pSK41 from the RepA_N plasmid family, the 5'UTR of repA can form two mutually exclusive structures, one of which (the OFF-structure) sequesters the repA ribosome binding site (RBS) and forms a putative rho-independent transcription terminator, whereas the other structure (the ON-structure) prevents the OFF-structure from forming (Kwong et al., 2006, 2008; Kwong and Firth, 2015). A plasmid-expressed antisense RNA can form a duplex with the repA $5^{\prime}$ UTR and prevent formation of the $\mathrm{ON}$-structure, thereby shifting the equilibrium toward the OFF-structure. Thus, increasing copy-number of the plasmid will increase the concentration of antisense RNA, which in turn will block replication initiation (Kwong et al., 2006, 2008; Weaver et al., 2009).

A prerequisite for regulation of gene expression by antisense RNAs is that the intra-cellular concentrations of these regulators tightly follow the concentration of the regulated plasmids. This is accomplished by strong constitutive expression of the asRNA combined with its rapid degradation (Pritchard et al., 1969), and the plasmid thus relies on an efficient host-encoded RNA decay machinery to correctly regulate its copy-number (Saramago et al., 2015). In S. aureus, the main enzymes in RNA degradation are the endoribonuclease RNase $\mathrm{Y}$, the $5^{\prime}-3^{\prime}$ exoribonuclease RNase J (RNase J1 and RNase J2), the $3^{\prime}-5^{\prime}$ exoribonuclease PNPase, the double-stranded RNase III, and the RNA helicase CshA (Giraud et al., 2015; Durand and Condon, 2018).

Staphylococcus aureus strain SA564 (Somerville et al., 2002) was originally isolated from a patient with toxic shock syndrome (Somerville et al., 2002). In the course of sequencing its genome, we discovered that it carries a plasmid of $27273 \mathrm{bp}$, which we named pSA564 (Giraud et al., 2015). This previously uncharacterized plasmid carries a $\beta$-lactamase gene and encodes a replication initiator protein belonging to the RepA_N family (Weaver et al., 2009). Here we show that pSA564 replication is regulated by a small antisense RNA, RNA1, which controls the expression of RepA. We furthermore show that the level of RNA1 is regulated by RNase J-dependent degradation, and that RNA1 accumulates in RNase J mutant strains. This accumulation inhibits RepA production, thus making RNase J an essential hostfactor for pSA564 replication. Since many plasmids are regulated by small unstable RNAs (Brantl, 2014), it is probable that this is an example of a general mechanism where RNase activities and specificities play an essential role in determining the hostrange of plasmids.

\section{RESULTS}

Analysis of the pSA564 sequence revealed that it encodes a protein belonging to the RepA_N family of replication proteins (Weaver et al., 2009), between coordinates 20,793 to 21,737. The plasmid furthermore encodes a beta-lactamase, a cadmium transporter and three enterotoxin genes, as well as several hypothetical protein genes (Supplementary Figure 1).

A GenBank analysis (performed in December 2019) showed that many $S$. aureus strains harbor plasmids highly similar to pSA564, with 683 sequenced plasmids encoding identical RepA_N proteins. More distantly related plasmids are also recognizably part of the same family; for example the pUSA300HOU-MS and pSK1 RepA_N proteins are 99\% and 68\% identical to pSA564 RepA_N, respectively (Table 1). The repA transcription start site (TSS) was mapped to position 20,596, 197 nucleotides upstream of the AUG start codon (Prados et al., 2016). Although the nucleotide sequence of the $5^{\prime} \mathrm{UTR}$ from pSA564 repA is different from that of pSK1 and pSK41 (Kwong et al., 2006, 2008; Kwong and Firth, 2015), the repA mRNA 5'UTR also has the potential to form two mutually exclusive stem-loop structures, UTR-SLII-ON vs. UTR-SLII-OFF and UTR-SLIII (Figures 1B,C). These are distinguished by a central CC dinucleotide ( $\mathrm{CC}^{\mathrm{MID}}$ ) which can base-pair with either an upstream or downstream GG dinucleotide $\left(\mathrm{GG}^{\mathrm{UP}}\right.$ and $\mathrm{GG}^{\mathrm{DW}}$, respectively). One of these two putative secondary structures sequesters the RBS of the repA gene while the other leaves it accessible to the ribosome (Figure 1).

\section{pSA564 Is Regulated by a Small Antisense RNA Upstream of the repA Start Codon}

The region upstream of the repA gene contains two divergent genes, rac and rep1. The former could potentially contribute to plasmid segregation, while the latter appears to be a rolling circle plasmid replication protein which has been inactivated by a frameshift mutation (Figure 2A). To examine whether pSA564 replication is regulated by a small transcript (in the same way as pSK1 and pSK41), we generated two constructs using the multi-copy vector pEB01 as backbone. pEB01 carries

TABLE 1 | Similarities between RepA from pSA564 and RepA from other staphylococcal plasmids.

\begin{tabular}{lccc}
\hline Plasmid name & Identity (\%) & Positive (\%) & RepA accession number* \\
\hline pN315 & 45 & 64 & BAB43870 \\
pSK1 & 68 & 79 & AAF63252 \\
pUSA300-HOU-MR & 45 & 63 & YP_001569048 \\
pUSA300-HOU-MS & 99 & 99 & YP_001569077 \\
\hline
\end{tabular}

*The accession number for pSA564 RepA is ALD82318. 


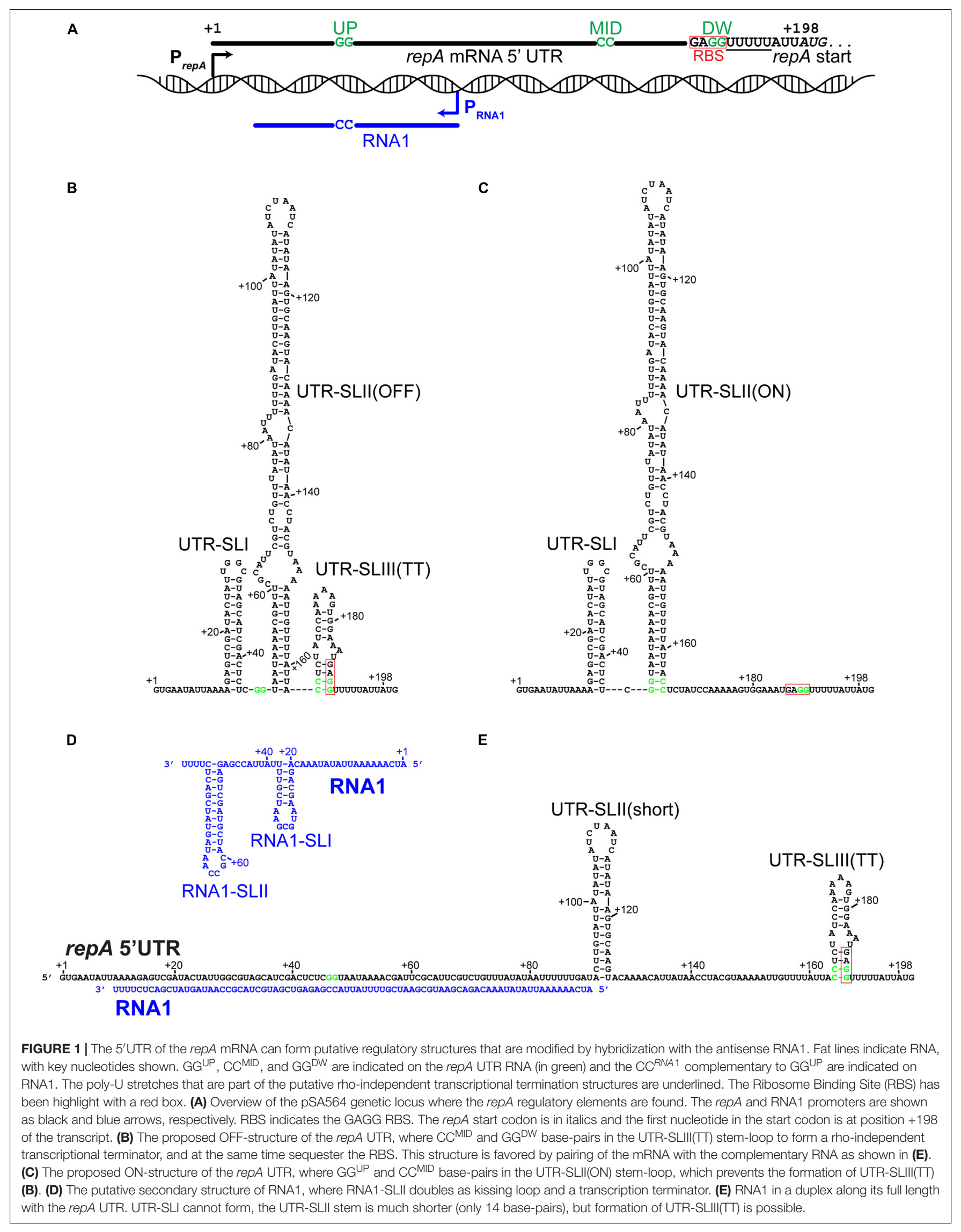




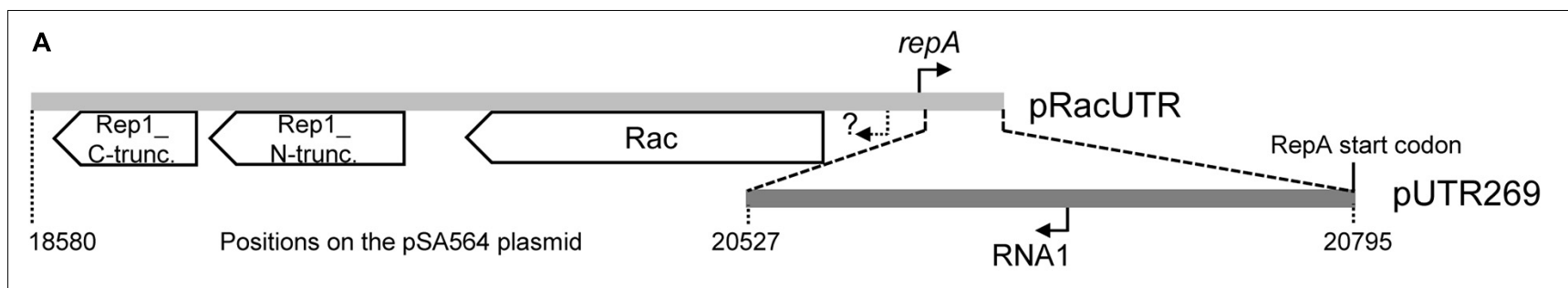

B

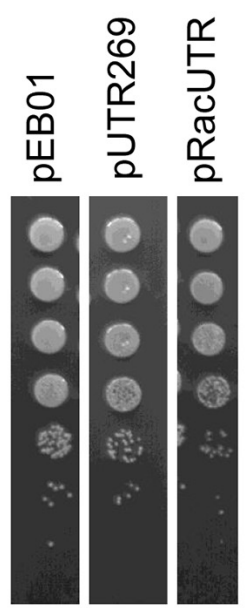

$\mathrm{MH}$

no selection

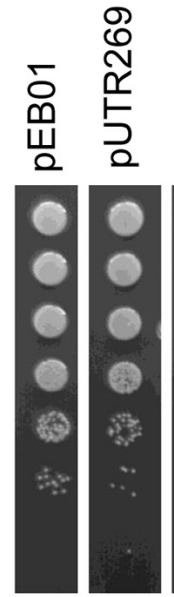

$\mathrm{MHC}$

selects for

pEB01/

pUTR269/

pRacUTR
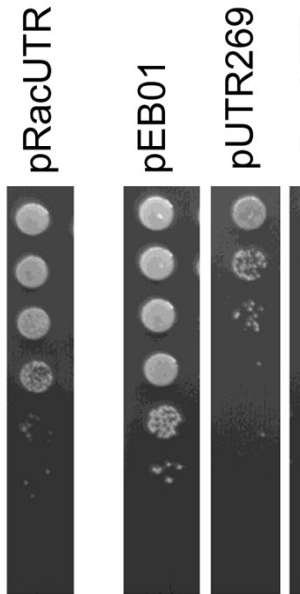

MHP

selects for

pSA564
C

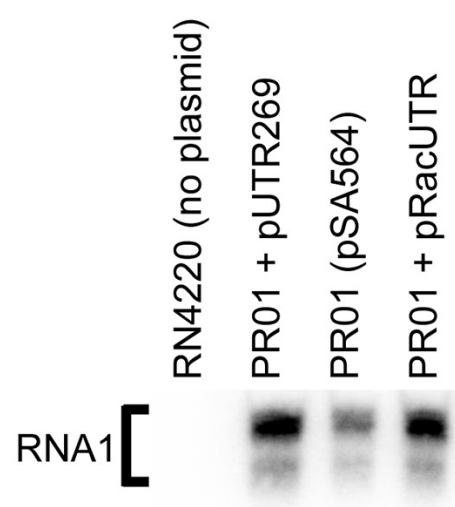

$5 S$

FIGURE 2 | An incompatibility factor is encoded within 269 bp of pSA564. (A) The region upstream of the repA gene contains two divergent genes, rac and rep1, where the latter has been split in two (and presumably inactivated) by a frameshift mutation to form rep1_N-truncation and rep1_C-truncation. The 2,216 bp region cloned into pRacUTR (light gray), includes the putative rac promoter (question mark) and the repA promoter. The 269 bp region cloned into pUTR269 (dark gray) includes the repA start codon and the RNA1 promoter, but not the repA promoter. (B) pSA564 is lost upon acquisition of either pRacUTR or pUTR269. Colonies from the transformation were picked, sequentially diluted 10-fold and spotted on Mueller-Hinton plates containing either no antibiotic, chloramphenicol, penicillin G, or both antibiotics. (C) Northern blotting shows a small antisense RNA, transcribed from pSA564 as well as from pRacUTR and pUTR269. The minor band observed below the main RNA1 signal is presumably a fragment of RNA1, since it is absent from the S. aureus strain RN4220 which carries no plasmid. Probe R1 was used to detect RNA1, and a probe against 5S rRNA was used as control.

a chloramphenicol resistance cassette and the pT181 origin for replication in S. aureus (Charpentier et al., 2004; Giraud et al., 2015). The first construct, pRacUTR, had an insert that contained a disrupted rep_1 gene, the putative partitioning gene $\mathrm{rac}$, as well as the promoter, $5^{\prime}$ untranslated region $\left(5^{\prime} \mathrm{UTR}\right)$ and start codon of the repA gene (Figure 2A and Supplementary Figure 1). The second construct, pUTR269, had a 269 bp fragment containing the repA $5^{\prime} \mathrm{UTR}$ and start codon (Figure 2A and Supplementary Figure 1).

Strain PR01 is a derivative of SA564 (the natural host of pSA564). It carries pSA564 but the restriction systems have been knocked out to allow transformation with plasmids isolated from E. coli. PR01 was transformed with pRacUTR and pUTR269. Transformant colonies were resuspended in $\mathrm{MH}$ broth and plated on $\mathrm{MH}$ with chloramphenicol (MHC, to detect pRacUTR and pUTR269), MH with penicillin (MHP, to detect pSA564), and
MH with both antibiotics (MHCP) (Figure 2B). The bacteria that received either pRacUTR or pUTR269 showed 2 orders of magnitude fewer colonies on penicillin plates, suggesting that the incoming pUTR269 or pRacUTR plasmids inhibited replication of the resident pSA564. In accordance with this, no colonies were formed on plates containing both antibiotics (Figure 2B), and we concluded that the 269 bp region cloned in pUTR269 contains an important incompatibility element. To determine whether this element could be an antisense RNA, a Northern blot was performed, which detected a small antisense RNA ( <100 nt), both in PR01 (which carries pSA564) and in the strains harboring plasmid pUTR269 or pRacUTR (Figure 2C). These data are all consistent with an antisense RNA based plasmid replication control system of the same type as pSK41 and pSK1 (Kwong et al., 2006, 2008; Kwong and Firth, 2015), and we decided to name the antisense RNA from pSA564 "RNA1." 


\section{Modification of RNA1 Alters Plasmid Incompatibility Characteristics}

The antisense RNA1 molecule potentially forms two stem loops (Zuker, 2003), RNA1-SLI and RNA1-SLII, where the downstream hairpin (SLII) doubles as a rho-independent transcriptional terminator due to the stretch of uridine residues that immediately follow it (Figure 1D). RNA1-SLII has a CGCCAA-loop, which could function as a "kissing loop" (Tomizawa, 1984; Forsdyke, 1995), i.e., the site of initial base-pairing between RNA1 and the repA mRNA 5'UTR (Figure 3D). RNA1 includes the dinucleotide $\mathrm{CC}^{\mathrm{RNA} 1}$, which is complementary to $\mathrm{GG}^{\mathrm{UP}}$, and will sequester it upon forming a duplex with the mRNA $5^{\prime} \mathrm{UTR}$, leaving $\mathrm{CC}^{\mathrm{MID}}$ free for pairing with $\mathrm{GG}^{\mathrm{DW}}$ (Figure 1E).
To evaluate the importance of the individual sections of RNA1 and the repA mRNA 5'UTR, we generated pVG1, a plasmid that replicates in $S$. aureus via the pSA564 replication machinery and origin (Figure 4A). Based on data from pSK1 (Kwong et al., 2008), we expected the pSA564 replicon to be within the rep1 to repA_N region (position 19005 to 21937) of pSA564, and this region was therefore cloned into plasmid pRLYC1, which carries a $S$. aureus chloramphenicol resistance gene and an origin of replication that is functional in E. coli but not in $S$. aureus (Supplementary Figure 1). pVG1 can therefore easily be cloned and modified in $E$. coli, but its $S$. aureus replication machinery and copy-number control are from pSA564.

We then examined how RNA1 controls repA expression by modifying pVG1 in several ways: (i) abolishing the

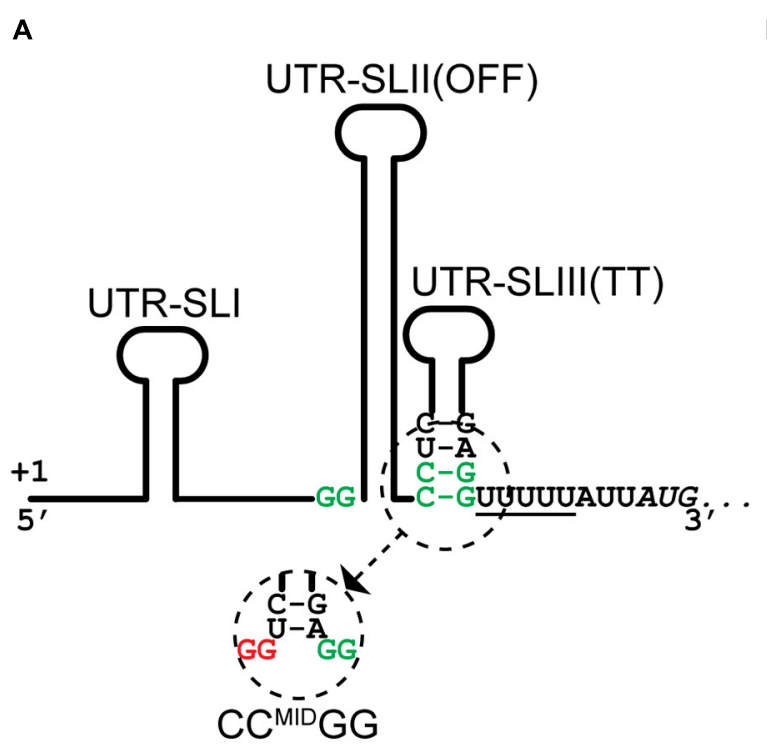

C

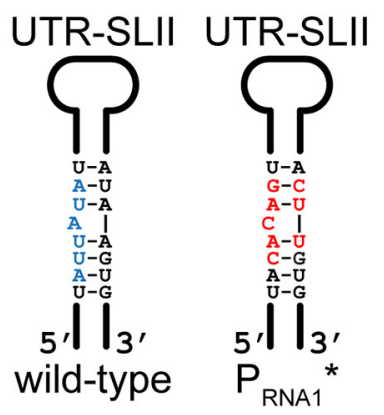

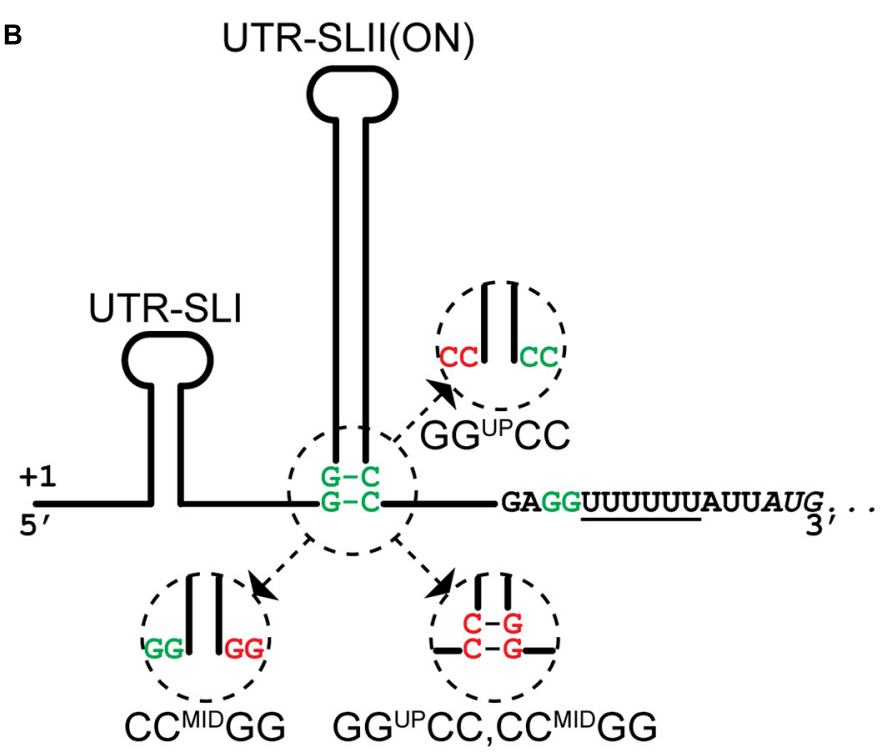

D

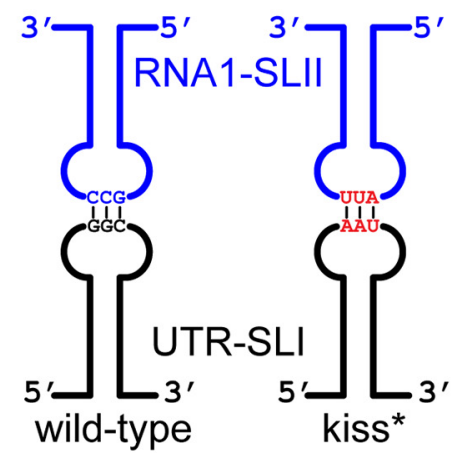

FIGURE 3 | Mutations that alters RNA1-repA mRNA interactions. (A) The CCMID GG mutation (red nucleotides in insert) prevents the formation of the putative

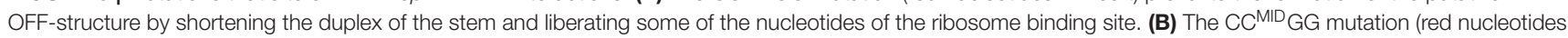
in insert) removes two base-pairs from the foot of the 46 base-pair UTR-SLII(ON) stem, in addition to preventing the putative OFF-structure from forming (A). The GGUPCC mutation (red nucleotides in insert) also weakens the UTR-SLII stem, which presumably shifts the equilibrium toward formation of UTR-SLIII(TT). The GGUPCC,CCMID GG mutation (red nucleotides in insert) allows the full length of the UTR-SLII(ON) stem to form, and at the same time weakens/prevents the UTR-SLIII(TT). (C) The $\mathrm{P}_{\mathrm{RNA} 1}{ }^{*}$ mutations in the -10 region of the RNA1 promoter (red nucleotides) do not disrupt base-pairing within the UTR-SLII (wild-type in blue). See also Supplementary Figure 2 for full nucleotide sequence. (D) The kiss* mutations (in red) weaken the base-base interactions between RNA1-SLII and UTR-SLI. See also Supplementary Figure 2 for full nucleotide sequence. 


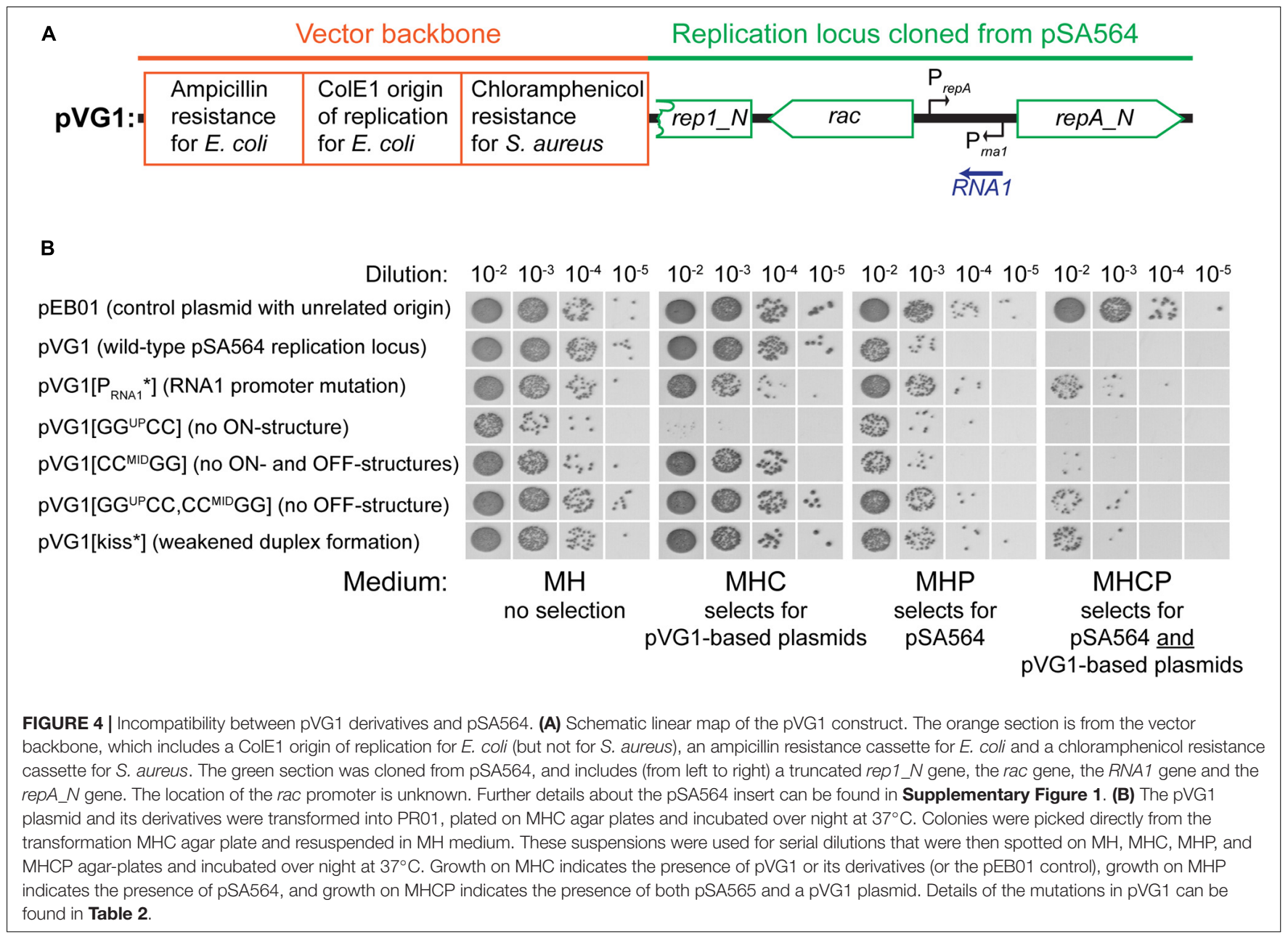

TABLE 2 | Overview of mutations in the repA $5^{\prime} U T R$.

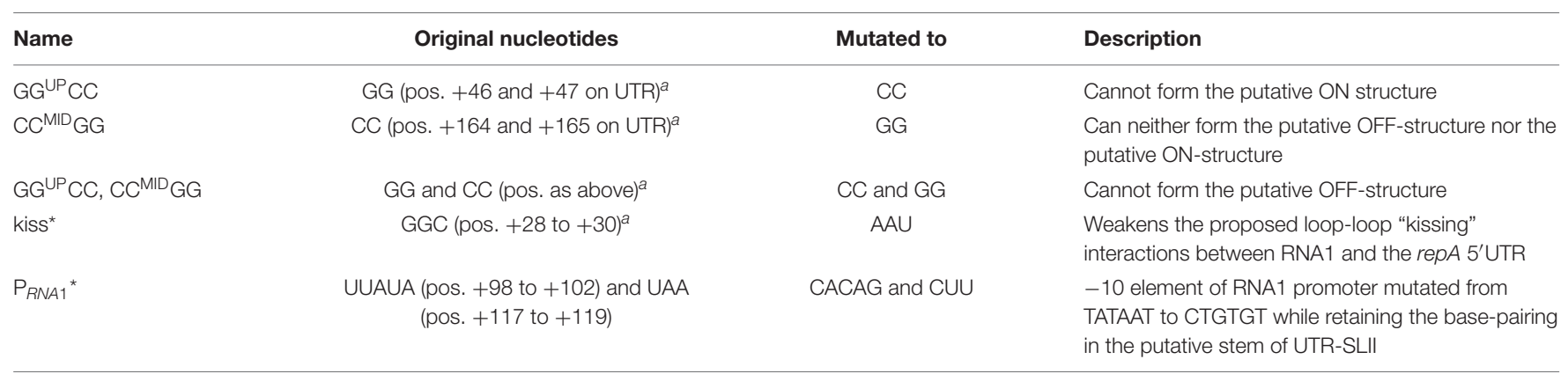

a These mutations also affect the sequence of the antisense RNA1.

production of RNA1 (pVG1[ $\left.\left.\mathrm{P}_{\mathrm{RNA} 1}{ }^{*}\right]\right)$, (ii) weakening the putative kissing interaction between the RNA1-SLII loop and the repA mRNA (pVG1[kiss]), (iii) reducing formation of both putative secondary structures of the $5^{\prime}$ UTR by mutating $\mathrm{CC}^{\mathrm{MID}}$ to $\mathrm{GG}$ (pVG1[CC $\left.{ }^{\mathrm{MID}} \mathrm{GG}\right]$ ), which at the same time will abolish duplex formation with the RBS, (iv) reducing formation of the proposed ON-structure of the $5^{\prime} \mathrm{UTR}$ by mutating GG ${ }^{\mathrm{UP}}$ to $\mathrm{CC}$ (pVG1[GG $\left.{ }^{\mathrm{UP}} \mathrm{CC}\right]$ ), or (v) reducing formation of the proposed OFF-structure of the $5^{\prime} \mathrm{UTR}$ by mutating both $\mathrm{GG}^{\mathrm{UP}}$ to $\mathrm{CC}$ and $\mathrm{CC}^{\mathrm{MID}}$ to $\mathrm{GG}$ (pVG1[GG $\left.{ }^{\mathrm{UP}} \mathrm{CC}, \mathrm{CC}^{\mathrm{MID}} \mathrm{GG}\right]$ ) (summarized in Table 2 and Figure 3). These mutant plasmids were then introduced into PR01 where transformant colonies were selected by growth on MHC. Then, 10-fold dilution series of these colonies were spotted on MHC, MHP, and MHCP to detect the presence of the pVG1 variant, pSA564 and pSA564 AND pVG1 variant, respectively (Figure 4). MH medium was also included, as control for growth without requirement for a plasmid.

pVG1 was able to replicate in PR01 (confirming that position 19,005 to 21,937 of pSA564 does indeed contain the replication locus). Furthermore, only about 1 out of 50 PR01 cells retain 
pSA564 after transformation with pVG1 and over-night selection on MHC (compare panel MH with panel MHP) and the complete lack of colonies on MHCP shows that pVG1 is incompatible with pSA564. This incompatibility is somewhat diminished with pVG1[P $\left.\mathrm{PNA1}^{*}\right]$, pVG1[GG ${ }^{\mathrm{UP}} \mathrm{CC}, \mathrm{CC}^{\mathrm{MID}} \mathrm{GG}$ and pVG1[kiss], where the combined pool of RepA from pSA564 and the pVG1 variant is apparently large enough to replicate both plasmids with simultaneous chloramphicol and penicillin selection (however, note the poor growth of these strains on MHCP, compared to the pEB01-carrying control strain). Cells transformed with pVG1[GG $\left.{ }^{\mathrm{UP}} \mathrm{CC}\right]$ grew poorly on $\mathrm{MHC}$ medium, consistent with a model where its $5^{\prime} \mathrm{UTR}$ is permanently in the putative OFF-structure, and $\mathrm{pVG} 1\left[\mathrm{GG}^{\mathrm{UP}} \mathrm{CC}\right]$ replication is therefore dependent on repA expression from endogeneous pSA564 (Figure 4). Importantly, neither the unrelated vector pEB01 (which carries pT181 replication machinery), nor growth on chloramphenicol in itself caused loss of pSA564.

To further analyze the role of RNA1 we also estimated the relative copy number of the plasmids by plating transformants on increasing concentrations of chloramphenicol. In the parental strain harboring pSA564, the resident plasmid could interfere with the copy number of pVG1, so the experiment was performed in PR02, a derivative of $S$. aureus RN4220 which harbors no plasmid. The wild-type version of the replicon, pVG1, was able to support growth up to $40 \mu \mathrm{g} / \mathrm{ml}$ chloramphenicol, whereas pVG1[GG $\left.{ }^{\mathrm{UP}} \mathrm{CC}, \mathrm{CC}^{\mathrm{MID}} \mathrm{GG}\right]$ and pVG1[CC $\left.{ }^{\mathrm{MID}} \mathrm{GG}\right]$ permitted growth at $60 \mu \mathrm{g} / \mathrm{ml}$ chloramphenicol, consistent with their inability to form the putative OFF-structure on repA mRNA (Figure 5). Strikingly, pVG1[ $\left.\mathrm{P}_{\mathrm{RNA} 1}{ }^{*}\right]$ permitted PR02 to grow at a chloramphenicol concentration equal to that seen with cells harboring pEB01, which carries the pT181 replication genes, origin of replication and copy-number control mechanism (resulting in an expected copy number of 20 to 25 copies per cell) (Charpentier et al., 2004; Oun et al., 2013). Note that repeated attempts to transform PR02 with pVG1[GG $\left.{ }^{\mathrm{UP}} \mathrm{CC}\right]$ yielded no transformants, and this strain is therefore not included in the assay.

\section{RepA Protein Expression Is Regulated by RNA1 and the 5'UTR Structure}

The observed differences in chloramphenicol resistance in Figure 5 could hypothetically be due to altered expression of the chloramphenicol resistance gene (for example via changes to supercoiling density), but the base-pair differences between the various pVG1 constructs are so small (maximum 12 substitutions) that we consider this an unlikely explanation. Nevertheless, to circumvent this potential problem, we decided to directly measure the RepA levels, and confirm that they are impacted by the ON-OFF equilibrium. We constructed a plasmid (pVG9) where RepA-expression is still under control of the equilibrium between structures of the UTR and regulated by RNA1, but where the copy-number of pVG9 is defined by the pT181 replication genes and origin. In addition, the RepA protein in pVG9 was C-terminally fused with a Streptavidin-Flag-tag, in order to follow the expression of RepA by Western blotting with an anti-Flag antibody (Figure 6A and Supplementary Figure 1). A strong band was observed for $\mathrm{pVG} 9\left[\mathrm{P}_{\mathrm{RNA}}{ }^{*}\right]$, which no longer produced RNA1 (Figure 6B). This band disappeared when the

A

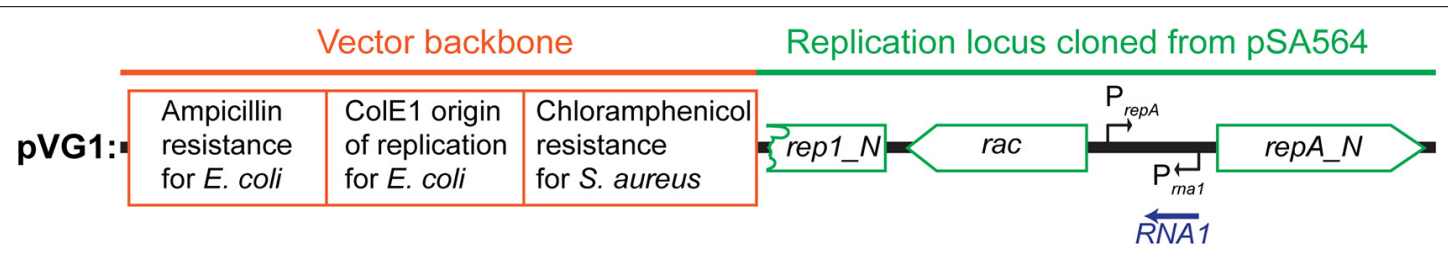

B

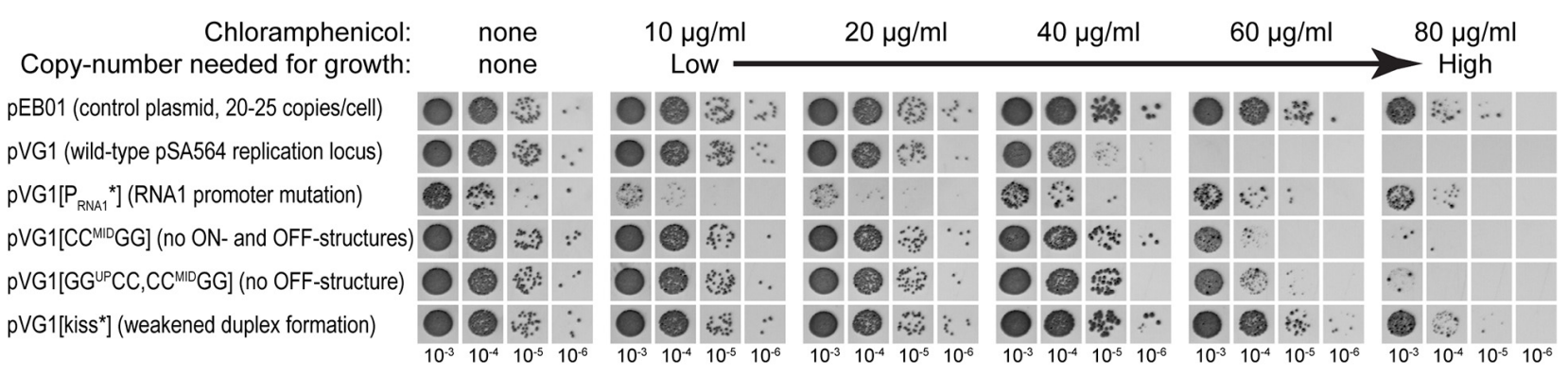

FIGURE 5 | RNA1 mutations affect plasmid copy-number. (A) Schematic linear map of the pVG1 construct. The orange section is from the vector backbone, which includes a ColE1 origin of replication for $E$. coli (but not for $S$. aureus), an ampicillin resistance cassette for $E$. coli and a chloramphenicol resistance cassette for S. aureus. The green section was cloned from pSA564, and includes (from left to right) a truncated rep1_N gene, the rac gene, the $R N A 1$ gene, and the repA_N gene. The location of the rac promoter is unknown. Further details about the pSA564 insert can be found in Supplementary Figure 1. (B) The copy number of pVG1 and its mutant derivatives was estimated by plating on medium containing increasing concentrations of chloramphenicol. Growth at higher concentrations indicate higher chloramphenicol resistance gene dosage (i.e., higher plasmid copy number). The experiment was carried out in the PR02 (a RN4220 derivative) host strain, and plasmid replication is therefore whole dependent on cis-produced RepA. Details of the mutations in pVG1 can be found in Table 2. 


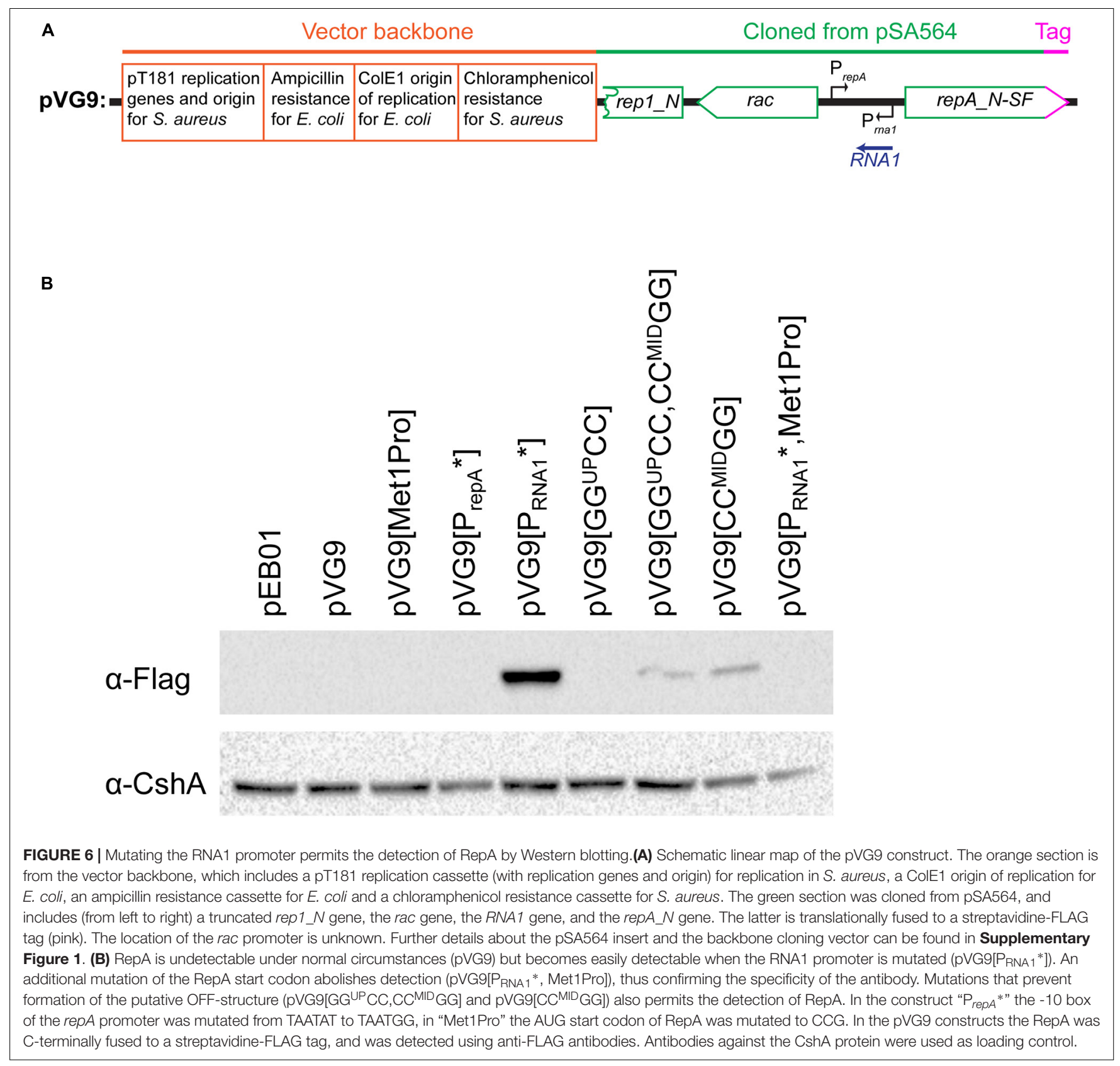

predicted repA start codon was mutated, not only confirming the identity of the detected protein but also experimentally verifying the annotation of the repA start codon (Figure 6B). It was also possible to detect a weak RepA expression from pVG1 [GG ${ }^{\mathrm{UP}} \mathrm{CC}$, $\left.\mathrm{CC}^{\mathrm{MID}} \mathrm{GG}\right]$ and pVG1[CC $\left.{ }^{\mathrm{MID}} \mathrm{GG}\right]$ (Figure 6B), corresponding to the strains in which the equivalent $\mathrm{pVG} 1$ derivatives exhibited increased copy-number (Figure 5B).

\section{RNase J Plays a Major Role in the Control of Plasmid Replication}

Mathematical modeling of negative regulators of plasmid replication which are constitutively expressed from the plasmid itself, predict that such regulatory molecules (e.g., RNA1) must have a short half-life (Pritchard et al., 1969). We therefore wanted to identify the host-factors needed to ensure rapid degradation of RNA1, and we argued that the lack of such a host-factor would lead to accumulation of RNA1 and subsequent loss of pSA564.

We had previously obtained mutants of PR01 (which naturally carries pSA564, since PR01 is a derivative of SA564) where we had deleted $c s h A, r n y, p n p A, r n j A$, and $r n j B$ (coding for CshA, RNase Y, PNPase, RNase J1 and RNase J2, respectively), and for this study, we additionnally generated a strain deleted for rnc (conding for RNase III). These mutants of the RNA decay machinery were spotted on penicillin plates to test for the presence of pSA564. All tested mutant strains were able to grow on penicillin, except $\Delta r n j A$ or $\Delta r n j B$ (Figure 7), leading us to 


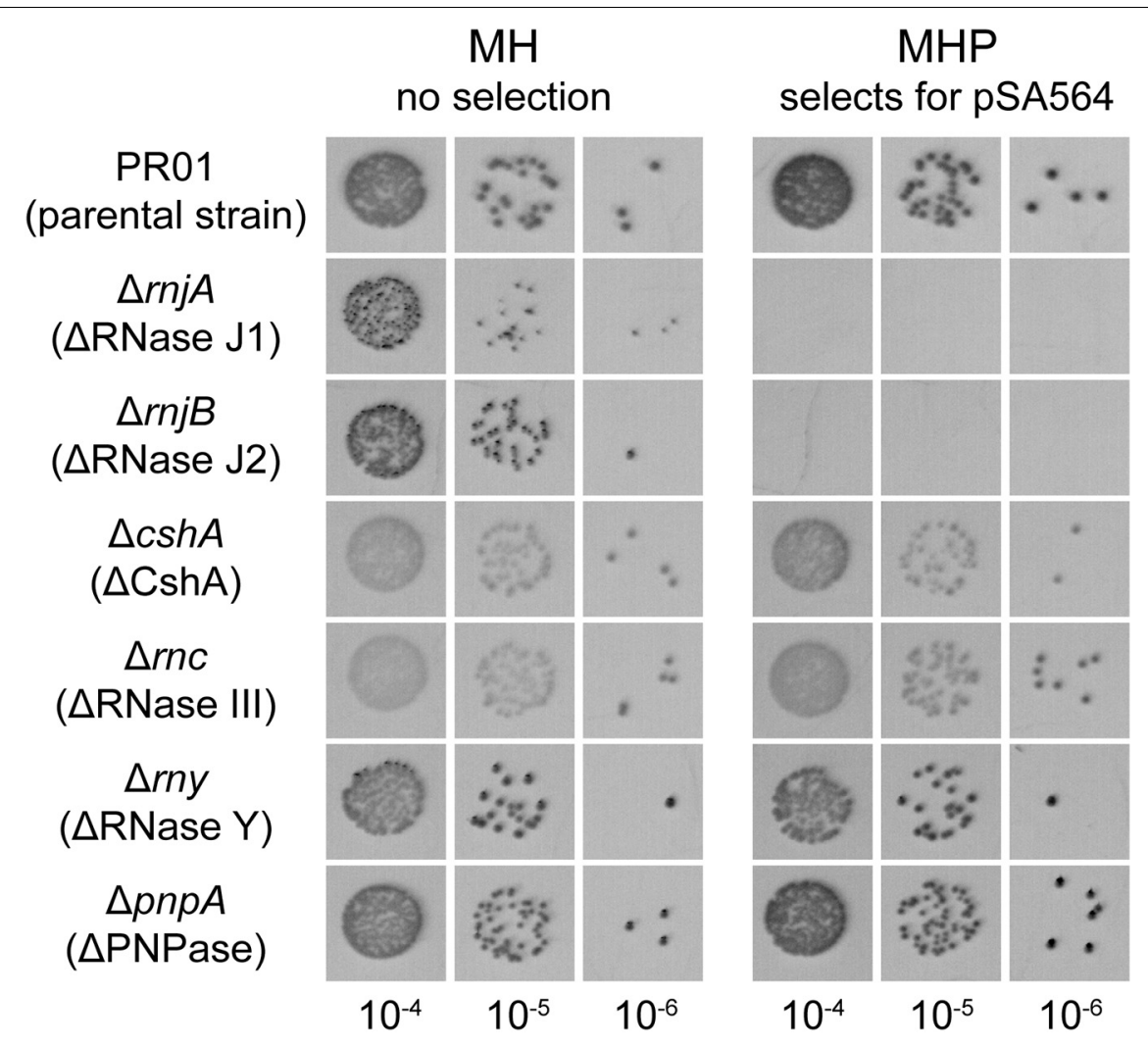

FIGURE 7 | pSA564 is lost in RNase J1 and J2 mutants. SA564-derived strains, mutated for different components previously identified to be part of the S. aureus RNA degradation machinery, were spotted on MH and MHP. The presence of pSA564 was determined by growth on MHP. The strains mutated for the two genes, rnjA and $r n j B$, encoding the $5^{\prime}-3^{\prime}$ ribo-exonucleases RNase $\mathrm{J} 1$ and RNase $\mathrm{J} 2$ were no longer able to form colonies on MHP plates.

suspect that RNase J1 and J2 were both required for degradation of RNA1 (and thereby for replication of pSA564).

RNase J1 and J2 mutants exhibit severe pleiotropic phenotypes (Linder et al., 2014). Therefore, to ensure that the penicillin sensitivity was not an artifact of these phenotypes, we re-analyzed our previously published whole genome sequencing data from our rnjA and $r n j B$ mutants (Linder et al., 2014) and confirmed that no pSA564-derived sequences could be detected, which established that our RNase J1 and J2 mutants strains had indeed lost pSA564. However, these strains were mutants that had been generated several years ago (Redder and Linder, 2012), and we had no direct proof that their parental strain was carrying pSA564 when the mutations were made. We therefore decided to generate a new rnjA deletion mutant, this time in a parental strain where we had verified the presence of pSA564 immediately before deleting $r n j A$. Once again, we observed that pSA564 was lost upon the introduction of the $r n j A$ mutation, proving that RNase $\mathrm{J} 1$ indeed is a key host-factor for this plasmid.

\section{RNA1 Is Overproduced in an rnjA Mutant}

To verify that loss of pSA564 in the RNase J mutant strains was directly linked to RNA1, we used pVG1 and pVG1[ $P_{\mathrm{RNA} 1}{ }^{*}$ ] which contain only the replicon from pSA564. If pVG1 [ $\left.\mathrm{P}_{\mathrm{RNA} 1}{ }^{*}\right]$ replicates in the $\triangle r n j A$ strain, while pVG1 does not, then RNase J1 must influence replication via RNA1. To ensure that variations in transformation efficiencies would not lead to bias, we co-transformed the two plasmids with the unrelated tetracycline resistance plasmid pCN36, in order to use the number of tetracycline resistant transformants as normalizer (Figure 8). The pVG1 $\left[\mathrm{P}_{\mathrm{RNA1}}{ }^{*}\right]$ was readily established in the $\triangle r n j A$ strain, whereas the pVG1 plasmid was not, demonstrating that RNA1 is essential for the plasmid-loss observed in RNase J mutants. Performing the same experiments with RN4220 (a control strain which does not harbor any plamids) revealed no significant difference between $\mathrm{pVG} 1$ and $\mathrm{pVG} 1\left[\mathrm{P}_{\mathrm{RNA} 1}{ }^{*}\right]$, except that colonies with pVG1 $\left[\mathrm{P}_{\mathrm{RNA} 1}{ }^{*}\right]$ were much smaller than colonies with pVG1 (Figure 8), presumably due to the added burden of un-controlled replication from the pSA564 origin.

To determine whether the plasmid-loss effect was due to an accumulation of RNA1 (as would be expected in a mutant deficient in RNA degradation), we examined the stability of RNA1 in the wild-type and $\triangle r n j A$ strains (Figure 9). We were unable to do this directly in the $\triangle r n j A$ strain, since it has lost the pSA564 plasmid, so we transformed both the $\Delta r n j A$ and the parental PR01 strains with pRacUTR, which replicates via the pT181 origin of replication and expresses RNA1 and the repA 5'UTR (but not the repA coding region). Both RNAs are transcribed from their natural promoters and all potential RNA-RNA duplex-forming regions are intact, so we expected this to mimic the natural situation from pSA564. Indeed, the 


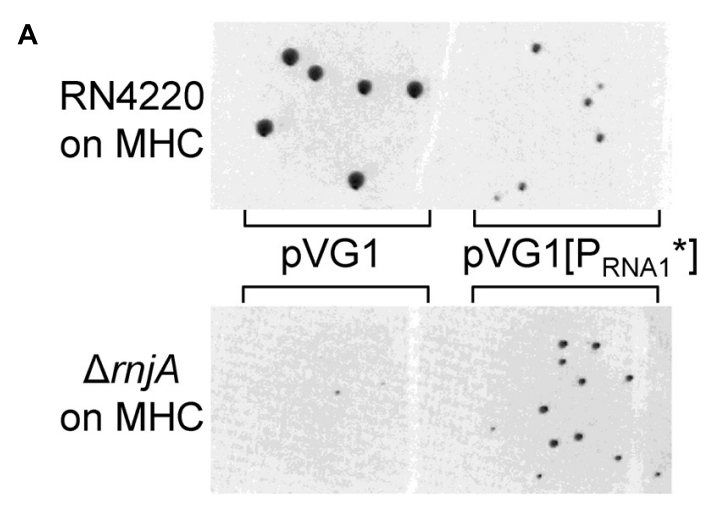

\section{B Colony ratio between chloramphenicol and tetracycline plates}

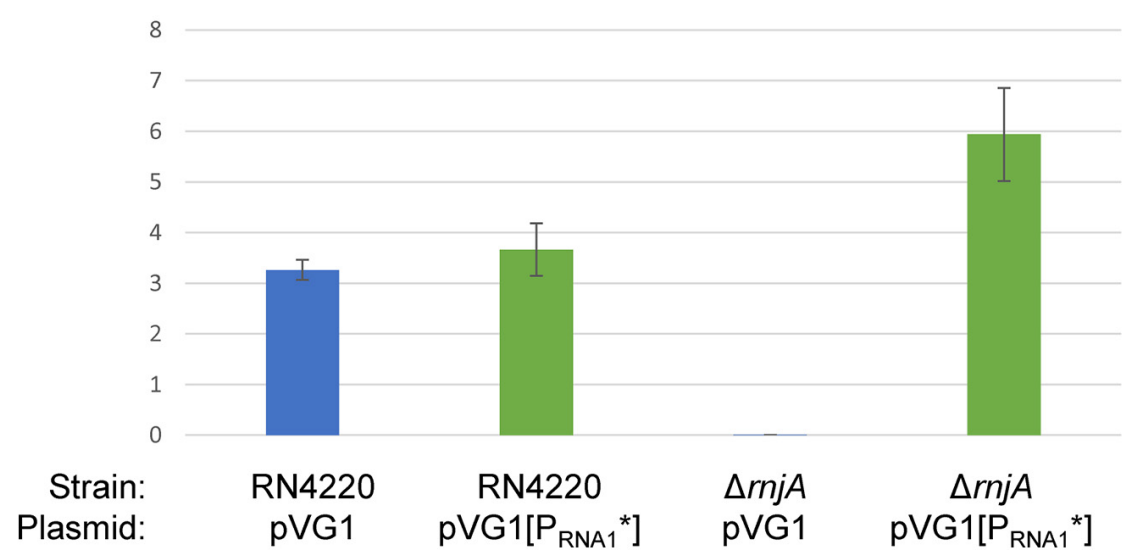

FIGURE 8 | RNA1 is essential for RNase J-deficient plasmid-loss. (A) Both pVG1 and pVG1[PRNA *] are able to establish themselves in RN4220 (an S. aureus strain

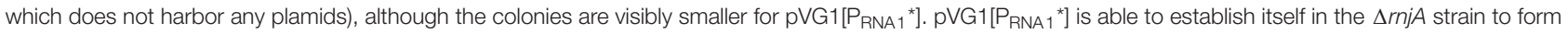
colonies in $24 \mathrm{~h}$. The RN4220 and the $\Delta r n j A$ colonies are from two different MHC-plates. (B) The colony counts from MHC-plates (pVG1 and pVG1[PRNA ${ }^{*}$ ] transformants) at $\sim 24 \mathrm{~h}$ were normalized with counts from MHT-plates (pCN36 transformants, counted at $\sim 42 \mathrm{~h}$ ). RN4220 exhibits similar colony, colony ratios for pVG1 and pVG1[P $\left.\mathrm{RNA}^{*}\right]$ (blue and green bars, respectively), whereas only pVG1[P $\mathrm{RNA}^{*}$ ] replicates rapidly in $\Delta r n j A$ to form colonies within $24 \mathrm{~h}$. Note that $\Delta r n j A$ transformed with pVG1 will eventually form colonies when the plates are left long enough in the incubator.

RNA1 levels in PR01 expressing RNA1 from pSA564 and from pRacUTR were similar (Figure 9B).

Northern blot analyses showed that the half-life of the longest RNA1 species increase 10-fold in the RNase J1 mutant (Figures 9C,D, compare the upper band in the two "0 $\mathrm{s}$ " lanes). To our slight surprise the level of longest RNA1 species remains similar in the wild-type and the $\Delta r n j A$ strains. However, several RNA1 fragments were observed to strongly accumulate in the $\triangle r n j A$ strain, due to a 17 -fold average increase in their halflives (Figure 9D).

\section{The 3'-Section of RNA1 Is Sufficient for Replication Inhibition}

We hypothesized that the 3 '-section of RNA1 which accumulates in $\triangle r n j A$ should be able to inhibit pSA564 replication. However, can such short RNA molecules still compete with the intramolecular secondary structures of the repA UTR to form an
RNA1-UTR duplex? And would such a duplex really prevent formation of the proposed ON-structure?

Inspection of the RNA1-UTR duplex and the putative secondary structures of the UTR suggested that RNA1 molecules truncated (or degraded) at their $3^{\prime}$ ends are likely to retain their ability to compete with the inferred UTR-SLII(ON) structure. However, RNA1 molecules that are truncated at their $5^{\prime}$ ends will overlap less with this UTR-SLII(ON) structure, and might therefore be less efficient in shifting the UTR to the OFFstructure. To determine the lower limit for a "competitive" RNA1 fragment, we constructed two versions of pRacUTR which express RNA1 molecules shortened at their $5^{\prime}$ ends by $18 \mathrm{nt}$ (pRNA1-18nt) and $38 \mathrm{nt}$ (pRNA1-38nt), respectively. It should be noted that both these truncated RNA1s carry the GG dinucleotide which is antisense to the key $\mathrm{CC}^{\mathrm{MID}}$ nucleotides of the UTR. pRNA1-18nt was incompatible with pSA564 (Supplementary Figure 3C). However, the shorter RNA1-38nt was unable to cause the loss of pSA564, and Northern blotting therefore detected both 


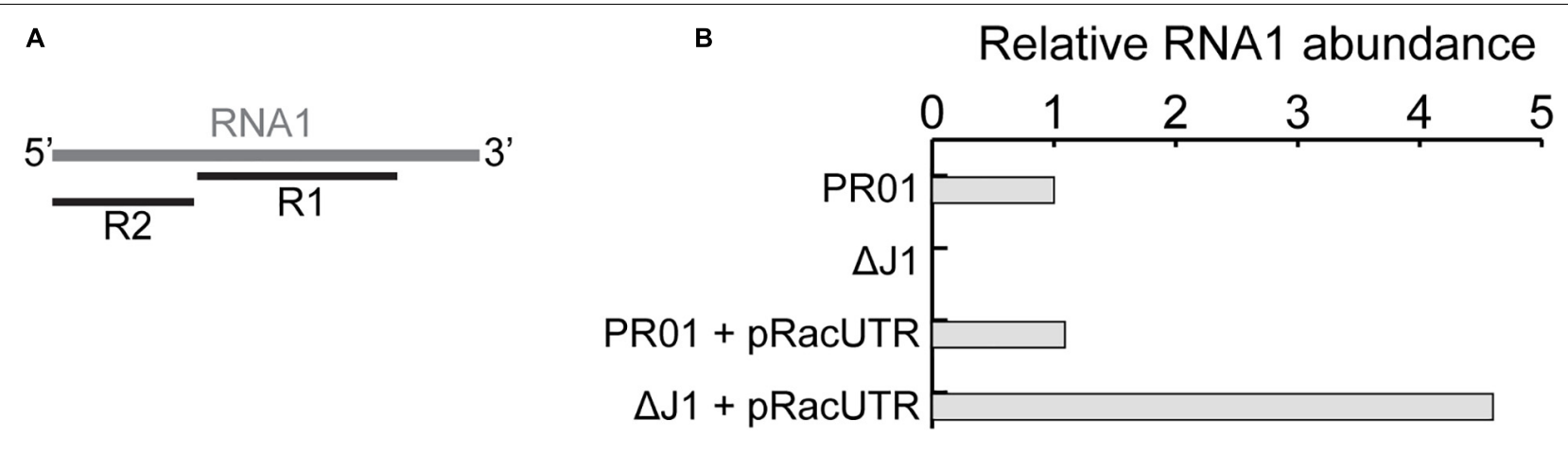

C

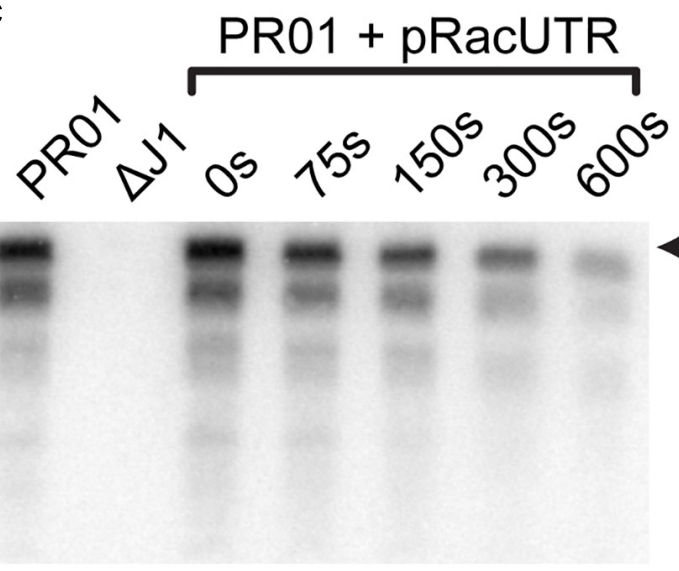

४Full length $>$

Probe R1

Longest RNA1 species: $\mathrm{T}_{1 / 2} \sim 3.5 \mathrm{~min}$

Longest RNA1 species: $T_{1 / 2} \sim 34 \mathrm{~min}$

All RNA1 fragments: $T_{1 / 2} \sim 3.0 \mathrm{~min}$

D

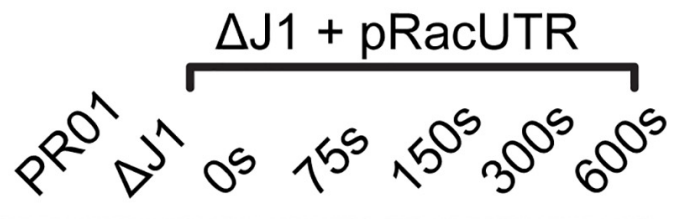

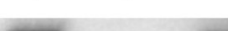
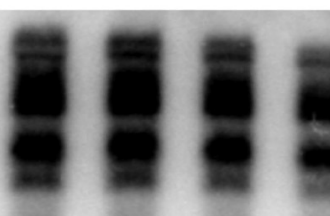

All RNA1 fragments: $T_{1 / 2} \sim 53 \mathrm{~min}$

E

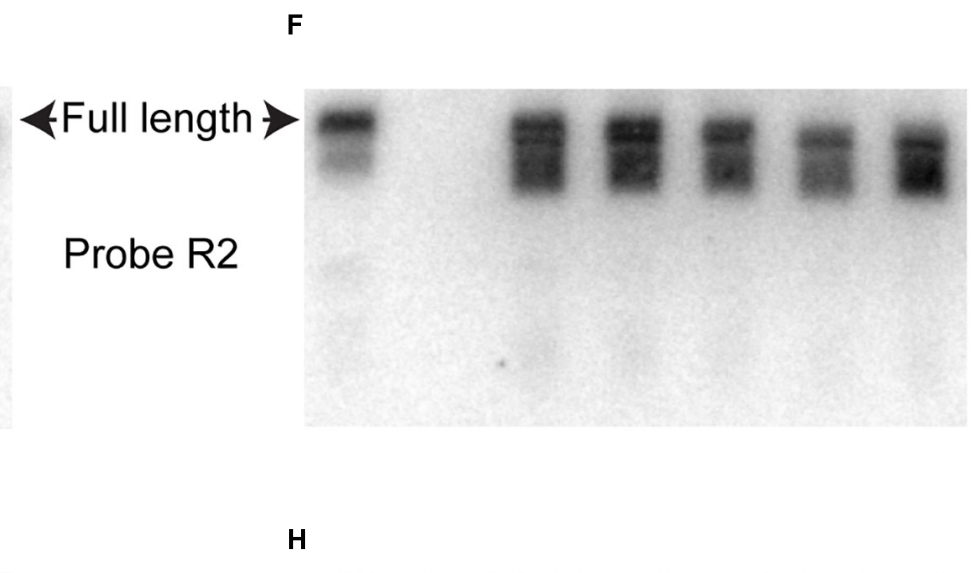

G

Probe 5S

FIGURE 9 | RNA1 degradation and abundance. (A) Overview of where probe R1 and R2 hybridizes on RNA1. (B) Level of RNA1 is similar for pSA564 and pRacUTR in PR01, but the overall intensity of the combined RNA1 bands are much higher in $\triangle r n j A$. (C,D) Rifampicin was used to block transcription and RNA was extracted at different time points to follow the rate of degradation by Northern blotting. The intensity of longest RNA1 species detected for each time-point was used to calculate the RNA1 half-life. However, RNA1 fragments accumulate in the $\Delta$ rnjA mutant, and these shorter RNA1 fragments cannot be readily quantified individually, so we here present the half-life of the combined signal of the R1 probe (i.e., all bands pooled). (E,F) A second probe (R2) against RNA1, this time targeting the $5^{\prime}$-end was used to re-probe the same membrane as in (C,D), respectively. (G) Probe against 5S rRNA to normalize the membrane shown in (C,E). (H) Probe against $5 \mathrm{~S}$ rRNA to normalize the membrane shown in (D,F). 
full-length RNA1 from pSA564 and RNA1-38nt from pRNA138nt (Supplementary Figure 3D).

\section{DISCUSSION}

Before this study, it was already known that the two RepA_Nfamily plasmids pSK1 and pSK41 produce a small antisense RNA as copy-number control molecule from the opposite strand of their repA_N 5'UTR. Our highly similar findings for pSA564 show that this asRNA could be a universal system for this plasmid family. Indeed, a survey of small RNAs from S. aureus N315, using next-generation sequencing, detected an uncharacterized antisense RNA in the $5^{\prime} \mathrm{UTR}$ region of the predicted repA_N gene of pN315 (Beaume et al., 2010), further strengthening this hypothesis.

\section{Genetic Analyses of the pSA564 Replication Control Mechanism}

Both pUTR269, which only carries a 269 bp region of pSA564, as well as pVG1, which replicates in $S$. aureus via a pSA564 minimal replicon, are incompatible with the extant pSA564 (Figures 2, 4). Moreover, mutations in the promoter region of RNA1 in pVG1 strongly increased compatibility with the endogenous pSA564 (Figure 4), confirming that RNA1 is an important incompatibility element.

An examination of the relative copy-number of the pVG1 variants (Figure 5) suggested that the lack of RNA1 (in pVG1 $\left.\left[\mathrm{P}_{\mathrm{RNA} 1}{ }^{*}\right]\right)$ increases the copy-number, as would be expected when an inbitor of RepA expression is removed. However, the bacteria grow poorly when carrying the plasmid without copy-number control (see colony size with pVG1 $\left[\mathrm{P}_{\mathrm{RNA} 1}{ }^{*}\right]$ in Figure 5B and compare left and right upper panel in Figure 8A), and we speculate that the uncontrolled plasmid replication results in a significant added burden to the cell. Interestingly, the mutation in the putative kissing loop of RNA1-SLII and UTR-SLI (pVG1[kiss*]) raised the copy-number to the same level as pVG1 $\left[\mathrm{P}_{\mathrm{RNA}}{ }^{*}\right]$ (Figure 5B), demonstrating that these three nucleotides play a key role in the regulatory mechanism. pVG1 $\left[\mathrm{GG}^{\mathrm{UP}} \mathrm{CC}, \mathrm{CC}^{\mathrm{MID}} \mathrm{GG}\right]$ and pVG1 [CC $\left.{ }^{\mathrm{MID}} \mathrm{GG}\right]$ exhibit an increased copy-number compared to pVG1 (Figure 5B), but their effect is smaller than for pVG1 $\left[\mathrm{P}_{\mathrm{RNA}}{ }^{*}\right]$ and pVG1 $\left[\right.$ kiss $\left.^{*}\right]$, suggesting that the $\mathrm{CC}^{\mathrm{MID}} \mathrm{GG}$ mutation does not completely eliminate negative regulation of RepA expression. pVG1[GGUP CC] prevents the ON-structure from sequestering the $\mathrm{CC}^{\mathrm{MID}}$ dinucleotide, and thus allows the full-length putative UTR-SLIII(TT) to form irrespective of RNA1. Our inability to transform PR02 with pVG1[GGUP CC], therefore suggests that RepA expression is completely abrogated when the stem of UTR-SLIII(TT) includes base-pairing between $\mathrm{CC}^{\mathrm{MID}}$ and $\mathrm{GG}^{\mathrm{DW}}$ (Figure 1B) (note that in contrast to PR01, PR02 cannot provide RepA in trans, since it does not carry pSA564; see Table 3).

The levels of RepA expressed from the various pVG9 mutants (Figure 6) correspond to the observations of relative plasmid copy number (Figure 5). The RepA control mechanism is designed to shut off expression when the copy number rises, and the medium-copy number of the pVG9 constructs (determined by the pT181 replication mechanism and origin) was therefore expected to lead to a firm repression of RepA expression. Furthermore, natural levels of RepA are presumed to be very low, since RepA from pSK41 was undetectable (Kwong et al., 2006; Liu et al., 2012). We were indeed unable to detect the RepA protein from $\mathrm{pVG}$ 9, presumably because the gene dosage of RNA1 goes up with increased copy-number. However, RepA becomes easily detectable when the RNA1 promoter is mutated (in pVG9 $\left[\mathrm{P}_{\mathrm{RNA}}{ }^{*}\right]$ ), confirming that RNA1 controls the level of RepA, which is necessary for the initiation of plasmid replication.

Taken together, the data from the pVG1 and pVG9 mutants of the repA_N $5^{\prime}$ UTR constitute compelling genetic evidence for a plasmid replication control model where RNA structures that are similar (or identical) to those proposed in Figure $\mathbf{1}$ are in an equilibrium, which is shifted according to the intracellular concentration of RNA1.

\section{RNase J1 Degradation of RNA1 Is Essential for pSA564 Replication}

Of the RNA decay mutants tested in this study, only RNase $\mathrm{J} 1$ and $\mathrm{J} 2$ mutants had lost pSA564 (Figure 7). RNase J1 and J2 have previously been proposed as essential for degrading the toxin mRNA in the par toxin-antitoxin system of pAD1 from Enterococcus faecalis (Shokeen et al., 2009), and we cannot exclude that pSA564 carries a similar par-like toxin-antitoxin system which killed all plasmid-carrying cells when RNase J1 or J2 was deleted (leaving only the cells that have lost pSA564 to form colonies). However, pVG1 only contains a short section of pSA564, without room for any putative toxin-antitoxin systems, and the lack of pVG1 replication in our RNase J1 mutant (Figure 8) therefore excludes that RNase $\mathrm{J} 1$ is needed for inhibiting toxin activity. Moreover, the lack of RNA1 is epistatic to the lack of RNase J1, since pVG1 $\left[\mathrm{P}_{\mathrm{RNA} 1}{ }^{*}\right]$ was able to replicate in the RNase J1 mutant (Figure 8). From this we conclude that RNase J1 (and presumably also RNase J2) promotes pSA564 replication via degradation of RNA1.

We examined RNA1 stability in the natural host of pSA564, and as expected it was quite short (about 3.5 min, Figure 9C), but we were able to detect a large half-life increase and concomittant accumulation of RNA1 fragments in the RNase J1 mutant (Figures 9D,F). We propose that these accumulating RNA1 fragments are responsible for blocking RepA expression (and consequent plasmid loss), and we show that RNA1 fragments with 18 nts missing from the $5^{\prime}$ end (RNA1-18nt) can indeed perform this role (Supplementary Figure 3). However, when $38 \mathrm{nts}$ are removed (and this includes the putative RNA1-SLI hairpin), then the inhibitory effect is abolished (Supplementary Figure 3), which suggests that the putative RNA1-SLI secondary structure is required for RNA1 to shift the equilibrium of the repA 5'UTR toward a structure that blocks RepA expression.

Our Northern blot revealed a slight decrease in the size of RNA1 after 300 and $600 \mathrm{~s}$ in the wild-type as well as in the $\Delta r n j A$ strain (Figures 9C,D), which is presumably due to "nibbling" by $3^{\prime}$ exoribonucleases. This hypothesis is further strengthened by the observation that some RNA1 fragments that accumulate in 
TABLE 3 | Strains.

\begin{tabular}{|c|c|c|c|c|}
\hline Short name & Strain name & Chromosomal genotype & Plasmid content & References \\
\hline SA564 & S. aureus SA564 & Parental strain & pSA564 & Giraud et al., 2015; Accession number: CP010890.1 \\
\hline RN4220 & S. aureus RN4220 & Parental strain & None & Nair et al., 2011 \\
\hline PR01 & PR01 & SA564 hsdR type III mutant $\Delta p y r F E$ & pSA564 & Redder and Linder, 2012 \\
\hline PR02 & PR02 & RN4220 $\Delta p y r F E$ & None & Redder and Linder, 2012 \\
\hline$\Delta$ RNase J1 & PR01-01 & PR01; $\Delta r n j A$ & None & Redder and Linder, 2012 \\
\hline$\Delta$ RNase J2 & PR01-04 & PR01; $\Delta r n j B$ & None & Redder and Linder, 2012 \\
\hline$\Delta$ RNase $Y$ & PR01-02 & PR01; $\Delta r n y$ & pSA564 & Redder and Linder, 2012 \\
\hline$\Delta$ RNase III & SVK97.1 & $\mathrm{PR} 01 ; \Delta r n c$ & pSA564 & This study \\
\hline$\triangle$ PNPase & PR01-07 & PR01; $\Delta p n p A$ & pSA564 & Redder and Linder, 2012 \\
\hline$\Delta \mathrm{Csh} A$ & PR01-15 & PR01; $\Delta c s h A: k a n A$ & pSA564 & Linder et al., 2014 \\
\hline$\Delta$ RNase J1new & VG_J1new & PR01; $\Delta r n j A$ & none & This study \\
\hline
\end{tabular}

the $\triangle r n j A$ mutant have been shortened at their $3^{\prime}$ ends (and are therefore still visible with the R2 probe) while others have lost their $5^{\prime}$ ends (visible with the $\mathrm{R} 1$ probe and undetected with the R2 probe) (Figures 9E,F).

Interestingly, the long RNA1 fragments that are visible with both the R1 and R2 probes in the $\triangle r n j A$ RNA are not detected in the wild-type strain (Figures $\mathbf{9 E}, \mathbf{F}$ ), and it seems likely that these are normally degraded from their $5^{\prime}$ end by the $5^{\prime}$ to $3^{\prime}$ exoribonucleolytic activity of RNase J1. In contrast, the fragments that have lost their $5^{\prime}$ ends in the $\triangle r n j A$ RNA (undetected with the R2 probe, compare Figures 9D,F), must have been generated by an unidentified endoribonuclease, and only then degraded by RNase J1. It therefore appears that RNase J1 is not always the initator of RNA1 degradation, but that RNase J1 is required for degrading the $3^{\prime}$ region of RNA1, i.e., a region which is sufficient for controlling pSA564 replication (see RNA1-18nt in Supplementary Figure 3).

RNases have previously been observed to be required for plasmid replication in Gram-negative bacteria via degradation of regulatory RNAs (Saramago et al., 2015 and references therein), but this has to our knowledge not previously been seen in Firmicutes. In E. coli, for example, it is RNase E which initiates degradation of the asRNAs RNAI and CopA, which negatively regulate replication of the plasmids ColE1 and R1, respectively (Lin-Chao and Cohen, 1991; Söderbom et al., 1997). The downstream RNase E cleavage products of RNAI and CopA are also able to inhibit plasmid replication (similar to RNA118nt, discussed above), and the rapid degradation of these intermediates requires the PAP I poly(A)polymerase. Mutating PAP I lowers the copy-numbers of both ColE1 and R1, but does not cure these plasmids (Xu et al., 1993; Söderbom et al., 1997). RNase E is unfortunately essential in E. coli, but it is possible that deleting RNase E would have the same dramatic effect that we observe for pSA564 when we delete RNase J1. Interestingly, S. aureus, B. subtilis, and many other Firmicutes encode neither RNase E nor PAP I homologs (Campos-Guillén et al., 2005; Durand et al., 2015), and it is possible that RNAI and CopA would be too stable to allow ColE1 and R1 replication in Firmicutes. Hfq, a protein which normally promotes RNARNA duplex formation in E. coli, appears to directly or indirectly prevent RNAI from interacting with the replication pre-primer RNAII, thus increasing replication of ColE1-like plasmids (Cech et al., 2014). While S. aureus does encode an Hfq homolog, it does not appear to be implicated in RNA-RNA interactions, suggesting a different organization of sRNA-mediated regulation (Bohn et al., 2007).

\section{Types and Activities of Host-Encoded RNases Could Be a Major Factor in Limiting Plasmid Host-Ranges}

We show here that RNase J1 and J2 are essential host-factors for pSA564 replication. Their activity will therefore be a key determinant for the host-range of pSA564. An NCBI database search (February 2019) revealed 94 plasmids with a repA UTR region with $100 \%$ identity to the pSA564 UTR and 22 plasmids in which the whole repA locus is identical to that of pSA564. Notable amongst these is pSA564-fus which was recently isolated from a Danish patient and is identical to pSA564 except for the additional presence of a $f u s B$ fusidic acid resistance cassette (Edslev et al., 2018). The dependence on RNase J probably extends to all plasmids with pSA564like replication origins, as well as to other members of the S. aureus RepA_N plasmid family, since all appear to be regulated by RNA1-UTR-type mechanisms and have narrow host-ranges (Weaver et al., 2009).

RNase J homologs are found in several bacterial phyla, but are conspicuously absent from Bacteroidetes, Chlamydiae, betaproteobacteria and the majority of gamma-proteobacteria (for example E. coli) (Laalami et al., 2014). Moreover, the Firmicutes generally encode at least two RNase J paralogs (for example RNase J1 and J2 in S. aureus). Each paralog has different activities and specificities, which are modified when the paralogs form a hetero-protein complex (Mathy et al., 2010; Linder et al., 2014; Raj et al., 2020). There is also variation in the relative importance of different RNases, depending on the species. For example, deletion of RNase J1 or J2 in S. aureus causes severe growth defects and leads to the accumulation of hundreds of RNA species (Linder et al., 2014), whereas in B. subtilis it is RNase $\mathrm{Y}$ deletion mutants that exhibit the most severe defects (Figaro et al., 2013). In addition, the $5^{\prime}$ exoribonuclease activity of RNase J homologs prefer substrates that are $5^{\prime}$ monophosphorylated, and each bacterial species encodes a different set of RNA pyrophosphohydrolases, which are enzymes that convert tri-phosphates into mono-phosphates at the $5^{\prime}$ ends of RNA (i.e., tri-phosphorylation of the +1 ribonucleotide into mono-phosphorylation) (Mathy et al., 2010; Hausmann et al., 2017; Srouji et al., 2017). 
These species-dependent variations between RNase J-proteins and the RNA pyrophosphohydrolases would modify the speed of RNA1 decay as well as the type of RNA1 fragments that accumulate, meaning that the copy-number of an RepA_N plasmid would be different in each potential host species. If the endogenous RNase J enzymes are not able to degrade RNA1 correctly, then the RepA_N plasmid would not replicate and if RNA1 is degraded too readily, then the RepA_N plasmid would replicate too fast and put a burden on the host cell (we observe this when the pVG1[ $\left.\mathrm{P}_{\mathrm{RNA} 1}{ }^{*}\right]$ construct leads to slow-growing colonies in Figures 5B, 8A). Such slower growing bacteria will presumably be outcompeted in nature, unless a continuous selection pressure is maintained (for example with penicillin).

As discussed above, it is expected that negative regulators of plasmid replication are rapidly degraded to ensure that plasmids can coordinate their replication with cell volume. RNAIII from pIP501 is an example of a very stable replication-inhibiting asRNA, with a half-life of about $30 \mathrm{~min}$ in B. subtilis (Brantl and Wagner, 1996). This should preclude proper copy-number control, and the authors propose an elaborate model where the plasmid-encoded transcriptional regulator CopR represses both RNAIII and its target repR mRNA in order to control replication (assuming that CopR has a short half-life; Brantl, 2015, and references therein). Intriguingly, pIP501 was discovered in Streptococcus agalactiae and presumably has a copy-number control mechanism which has evolved to fit the RNA decay system in that bacterium. Little is known about RNA decay in $S$. agalactiae, but both RNase $\mathrm{J} 1$ and $\mathrm{J} 2$ are essential in Streptococcus pyogenes, whereas they are both non-essential in B. subtilis (Bugrysheva and Scott, 2010; Figaro et al., 2013). It is therefore possible that while RNAIII exhibits a long half-life in B. subtilis (Brantl and Wagner, 1996), it may have a short half-life (leading to more precise copy-number control) in S. agalactiae where the activity and specificity of the RNA degradation system might be different than in B. subtilis.

The host-range of the RepA_N family plasmids is of clinical relevance, since they readily pick up antibiotic resistance cassettes and virulence factors from the chromosome or other plasmids (Weaver et al., 2009; Liu et al., 2013), and their horizontal dispersal therefore directly impacts global health. The importance of an RNase as essential host-factor is highlighted by the fact that the copy-number of many other plasmid families (e.g., ColEI, R1 and pT181) is also regulated negatively by short RNA molecules (del Solar and Espinosa, 2000). The paradigm for such regulation is that the regulating molecule must be shortlived (Pritchard et al., 1969; Wagner and Brantl, 1998), and it is therefore probable that RNase activities and specificities play a large role in determining the host-range of plasmids in general.

\section{MATERIALS AND METHODS}

\section{Staphylococcus aureus Strains and Growth Conditions}

Strains and plasmids used in this study are described in Tables 3, 4, respectively.
The Escherichia coli $\mathrm{DH} 5 \alpha$ strain was grown in $\mathrm{LB}$ medium supplemented, if necessary, with $100 \mathrm{mg} / \mathrm{l}$ ampicillin (SigmaAldrich, Buchs, Switzerland). The $S$. aureus strains were cultivated in Mueller-Hinton broth supplemented with $20 \mathrm{mg} / \mathrm{l}$ uracil $(\mathrm{MH})$ and when needed with $10 \mathrm{mg} / \mathrm{l}$ erythromycin (MHE), $10 \mathrm{mg} / \mathrm{l}$ chloramphenicol (MHC), $2 \mathrm{mg} / \mathrm{l}$ tetracyclin (MHT), $240 \mu \mathrm{g} / \mathrm{l}$ of penicillin G (MHP) (Sigma-Aldrich, Buchs, Switzerland), or a combination of chloramphenicol and penicillin G (MHCP). Agar plates contained $13 \mathrm{~g} / \mathrm{l}$ of agar (Agar bacteriology grade, PanReac AppliChem). Strain PR01 is a derivative of SA564 where the restriction systems have been inactivated to facilitate transformation, and the pyrFE genes have been deleted to facilitate genetic manipulations, but where pSA564 replication remains unchanged (Corvaglia et al., 2010; Redder and Linder, 2012). Strain PR02 is a derivative of $S$. aureus RN4220, where the pyrFE genes have been deleted (Redder and Linder, 2012). Mutants SVK97.1 and VG_J1new were generated from PR01 using the protocol described previously (Redder and Linder, 2012).

\section{Molecular Biology Methods}

All methods of standard molecular biology techniques used, were performed by the methods of Molecular cloning: a laboratory manual (Sambrook and Russel, 2001) or according to the recommendations of the manufacturers. Restriction enzymes were from New England Biolabs (Ipswich, MA, United States) and PCR products used for cloning were amplified using Q5 ${ }^{\circledR}$ High-Fidelity DNA Polymerase (New England Biolabs).

Primers used for vector construction are shown in Supplementary Table 1 in the Supplementary Material.

Sequencing of plasmids for verification was done at Fasteris SA (Plan-les-Ouates, Switzerland) and full genome sequencing was performed by the iGE3 genomics platform of Geneva University.

\section{Transformation Experiment}

$1 \mu \mathrm{g}$ of the chloramphenicol resistance plasmids pVG1 and pVG1 $\left[\mathrm{P}_{\mathrm{RNA} 1}{ }^{*}\right]$ were each mixed with $250 \mathrm{ng}$ pCN36 control plasmid, which carries a tetracyclin resistance cassette. The two plasmid mixtures were transformed into RN4220 and PR0101 strains and plated on MHC and MHT plates. pVG1 and pVG1 $\left[\mathrm{P}_{\mathrm{RNA} 1}{ }^{*}\right]$ transformation is scored as the number of colonies growing on MHC divided by the number of colonies growing on MHT. RN4220 was chosen as control strain, since the parental strain of the PR01-01 strain carries pSA564 (which would compete with the pVG1 plasmids). The colonies were counted after $24 \mathrm{~h}$ incubation, except for PR01-01 on MHT, where it takes $40 \mathrm{~h}$ to grow visible colonies.

\section{Spotting Dilutions to Determine Growth Defects}

All the different strains were cultivated overnight in $\mathrm{MH}$ liquid medium supplemented with adequate antibiotics if needed. Dilution series were then made in $\mathrm{MH}$ medium, to obtain $10^{-2}$ to $10^{-6}$ dilutions, $7.5 \mu \mathrm{l}$ of which were spotted on $\mathrm{MH}$ medium and on $\mathrm{MH}$ supplemented with the appropriate antibiotic. Subsequently, the plates were incubated at $37^{\circ} \mathrm{C}$ until 
TABLE 4 | Plasmids.

\begin{tabular}{|c|c|c|c|}
\hline Plasmid name & Parent & Comment & References \\
\hline pSA564 & N/A & Penicillin resistance. Accession number: CP010891.1 & Giraud et al., 2015 \\
\hline $\mathrm{pCN} 47$ & N/A & Erythromycin resistance & $\begin{array}{l}\text { Charpentier et al., } \\
2004\end{array}$ \\
\hline pCN36 & $\mathrm{N} / \mathrm{A}$ & Tetracyclin resistance & $\begin{array}{l}\text { Charpentier et al., } \\
2004\end{array}$ \\
\hline pEB01 & $\mathrm{pCN} 47$ & $\begin{array}{l}\text { Chloramphenicol resistance; pT181 origin for S. aureus and ColE1 origin for } \\
\text { E. coli }\end{array}$ & Oun et al., 2013 \\
\hline pSauJ1 $^{\Delta} 2-565$ & pEB01 & $\begin{array}{l}\text { SA0941 and its promoter with the start codon of the following gene fused } \\
\text { directly to a streptavidin-flag tag }\end{array}$ & $\begin{array}{l}\text { Hausmann et al., } \\
2017\end{array}$ \\
\hline pRLYC1 & $\mathrm{N} / \mathrm{A}$ & $\begin{array}{l}\text { Chloramphenicol resistance; no replication origin for S. aureus, ColE1 origin } \\
\text { for E. coli }\end{array}$ & $\begin{array}{l}\text { Redder and Linder, } \\
2012\end{array}$ \\
\hline pUTR269 & pEB01 & Nucleotides 20527-20795 from pSA564 cloned into Sall and BamHI & This study \\
\hline pRacUTR & pEB01 & Nucleotides 18580-20795 from pSA564 cloned into Sall and BamHI & This study \\
\hline pVG1 & pRLYC1 & Nucleotides 19005-21937 from pSA564 cloned into Sall and BamHI & This study \\
\hline pVG1[GGUPCC] & pVG1 & GG to $\mathrm{CC}$ (pos. +46 and +47 on UTR) & This study \\
\hline pVG1[CC $\left.{ }^{\mathrm{MID}} \mathrm{GG}\right]$ & pVG1 & CC to GG (pos. +164 and +165 on UTR) & This study \\
\hline $\mathrm{pVG} 1\left[\mathrm{GG} \mathrm{UP}^{\mathrm{CC}}, \mathrm{CC}^{\mathrm{MID}} \mathrm{GG}\right]$ & pVG1 & $\begin{array}{l}\text { GG to CC (pos. }+46 \text { and }+47 \text { on UTR) and CC to GG (pos. }+164 \text { and } \\
+165 \text { on UTR) }\end{array}$ & This study \\
\hline pVG1[kiss*] & pVG1 & GGC to AAT (pos. +28 to +30 on UTR) & This study \\
\hline $\mathrm{pVG1}\left[\mathrm{P}_{\mathrm{RNA1}}{ }^{*}\right]$ & pVG1 & $\begin{array}{l}\text { TTATA to CACAG (pos. }+98 \text { to }+102 \text { on UTR) and TAA to CTT (pos. }+117 \\
\text { to }+119 \text { on UTR) }\end{array}$ & This study \\
\hline pVG9 & pSauJ1 $^{\Delta} 2-565$ & $\begin{array}{l}\text { Nucleotides } 19005-21734 \text { from pSA564 inserted between Sall and Agel, } \\
\text { which removes the SA0941 and its promoter, but leaves the } \\
\text { streptavidin-flag tag fused to the C-terminal of RepA }\end{array}$ & This study \\
\hline pVG9[GGUP CC] & pVG9 & GG to CC (pos. +46 and +47 on UTR) & This study \\
\hline pVG9[CC $\left.{ }^{\mathrm{MID}} \mathrm{GG}\right]$ & pVG9 & CC to GG (pos. +164 and +165 on UTR) & This study \\
\hline pVG9[GG $\left.{ }^{U P} C C, C C^{M I D} G G\right]$ & pVG9 & $\begin{array}{l}\text { GG to CC (pos. }+46 \text { and }+47 \text { on UTR) and CC to GG (pos. }+164 \text { and } \\
+165 \text { on UTR) }\end{array}$ & This study \\
\hline pVG9[kiss*] & pVG9 & GGC to AAT (pos. +28 to +30 on UTR) & This study \\
\hline $\mathrm{pVG} 9\left[\mathrm{P}_{\mathrm{RNA1}}{ }^{*}\right]$ & pVG9 & $\begin{array}{l}\text { TTATA to CACAG (pos. }+98 \text { to }+102 \text { on UTR) and TAA to CTT (pos. }+117 \\
\text { to }+119 \text { on UTR) }\end{array}$ & This study \\
\hline pVG9[Met1Pro] & pVG9 & AUG to CCG (pos. +198 to +200 on UTR) & This study \\
\hline pVG9[P repA $\left.{ }^{*}\right]$ & pVG9 & TAATAT to TAATGG (pos. 20584-20589 on pSA564) & This study \\
\hline pVG9[P repA ${ }^{\star}$, Met1Pro $]$ & pVG9 & $\begin{array}{l}\text { TAATAT to TAATGG (pos. 20584-20589 on pSA564) and AUG to CCG } \\
\text { (pos. }+198 \text { to }+200 \text { on UTR) }\end{array}$ & This study \\
\hline
\end{tabular}

the WT colonies reached an appropriate size for photography. All the strains compared in the figures were spotted on the same agar plate.

\section{RNA Isolation}

For RNA isolation, cultures were grown until mid-exponential phase $\left(\mathrm{OD}_{600}\right.$ of $\left.\sim 0.4\right)$ and harvested by rapidly mixing with five volumes of cold ethanol/acetone (1:1 vol:vol). Cells were pelleted $(4,000 \mathrm{~g}$ for $5 \mathrm{~min})$, washed in $1 \mathrm{ml}$ TE buffer, resuspended in $200 \mu \mathrm{T} \mathrm{TE}$ with $10 \mu \mathrm{g}$ Lysostaphin (Sigma) and $40 \mathrm{U}$ $\mathrm{RNasin}^{\circledR}$ Plus (Promega), and incubated at $37^{\circ} \mathrm{C}$ for $10 \mathrm{~min}$. The lysed cells were mixed with $750 \mu \mathrm{l}$ of TRIzol ${ }^{\mathrm{TM}}$ Reagent (INVITROGEN) and $150 \mu \mathrm{l}$ of chloroform. The samples were shaken vigorously for $15 \mathrm{~s}$ and left at room temperature for 3 min. Phase Lock Gel tubes (5prime, Hilden, Germany) were used to separate the phases, according to the manufacturer's protocol. Approximately $300 \mu \mathrm{l}$ of the solution from the aqueous phase were then transferred into a new $1.5 \mathrm{~mL}$ microcentrifuge tube. $20 \mu \mathrm{g}$ of RNase-free glycogen was added, together with $375 \mu \mathrm{l}$ cold isopropanol. The samples were then vortexed and stored overnight at $-20^{\circ} \mathrm{C}$. The RNA was pelleted by $40 \mathrm{~min}$ of centrifugation at $12,000 \times g$ and $4^{\circ} \mathrm{C}$. The supernatant was discarded, whereupon the pellet was washed with $1 \mathrm{~mL}$ of $75 \%$ cold ethanol and then centrifuged for $10 \mathrm{~min}$ at 7,500 $\times g$ at $4^{\circ} \mathrm{C}$. The supernatant was discarded; the pellet was air dried for 15-20 min and the RNA pellet was resuspended in $20 \mu \mathrm{L}$ of TE $1 \times$ buffer.

\section{RNA Half-Life Determination}

Overnight cultures were diluted 1:100 into fresh media and grown to $\mathrm{OD}_{600}$ of $\sim 0.4 .400 \mu \mathrm{g} / \mathrm{ml}$ rifampicin was added to the cultures and samples were taken at five time points: $0,75,150,300$, and 600 s. Each sample of $6 \mathrm{ml}$ was harvested by rapid mixing with $30 \mathrm{ml}$ cold 1:1 ethanol:acetone solution.

\section{Northern Blot}

Northern Blots were performed as in Khemici et al. (2015) with $8 \%$ acrylamide gels containing $8 \mathrm{M}$ urea. 4 to $8 \mu \mathrm{g}$ of total RNA (depending on experiment) was loaded in each 
lane and the marker was RiboRuler Low Range RNA Ladder (Thermo Scientific). The RNA migration was performed for $2 \mathrm{~h}$ at $90 \mathrm{~V}$. After electrophoresis, the RNA was transferred to a Hybond-N + membrane (GE Healthcare) for $2 \mathrm{~h}$ at $30 \mathrm{~V}$ and $0^{\circ} \mathrm{C}$, whereupon the RNA was UV crosslinked to the membrane $\left(120 \mathrm{~kJ} / \mathrm{cm}^{2}\right.$ Joules with a Stratalinker 2,400, Stratagene). Methylene blue staining was used to visualize the marker. The DNA oligo probes were $5^{\prime}$ labeled with ATP $\left[\gamma_{-}{ }^{32} \mathrm{P}\right]$ and Polynucleotide Kinase (Thermo Fischer Scientific) and hybridized to the membrane over night at $37^{\circ} \mathrm{C}$ in ExpressHyb hybridization solution (Clontech, Mountain View, CA, United States). The signals were detected using a Typhoon FLA 7000 phosphorimager (General Electric). The membranes were stripped for $2 \mathrm{~h}$ with stripping solution $(0.2 \%$ SDS and $10 \mathrm{mM}$ Tris $\mathrm{pH}$ 7.5) before each new hybridization, and the stripping was verified by phosphoimager. Probe R1: TTGGCGTAGCATCGACTCTCGGTAATAAAACGATTCGCA, Probe R2: ATTCGTCTGTTTATATAATTTTTTG, 5S rRNA probe: TTAACTTCTGTGTTCGGCATGGGAACAGGTGTGA CCTCC.

\section{Western Blot}

Bacterial cultures at $\mathrm{OD}_{600}$ of $\sim 0.4(20 \mathrm{~mL})$ were centrifuged $\left(5,000 \times g, 4^{\circ} \mathrm{C}, 10 \mathrm{~min}\right)$ and the pellet was lysed with $1 \mathrm{~mL}$ of PBS buffer ( $\mathrm{MgCl} 2+\mathrm{CaCl} 2)$ (DPBS D8662, SigmaAldrich), anti-protease (cOmplete, Mini, EDTAfree Protease Inhibitor Cocktail, Sigma-Aldrich), lysostaphin (Ambi products, Lawrence, NY, United States) to a final concentration of 200 $\mu \mathrm{g} / \mathrm{ml}$ and DNase I (M0303S; New England Biolabs) at a final concentration of $1 \mu \mathrm{l} / \mathrm{ml}$ for $15 \mathrm{~min}$ at $37^{\circ} \mathrm{C}$. Protein levels were quantified by Bradford solution diluted five times (Bio-Rad Assay Dye Reagent Concentrate, \#500-0006). Equal amounts (10 to $20 \mu \mathrm{g}$ total protein) of lysates were prepared in loading buffer $(4 \mathrm{x}=$ bromophenol blue $0,4 \%+200 \mathrm{mM}$ Tris $\mathrm{pH} 6,8+40 \%$ glycerol $+8 \%$ SDS), migrated on precast $8 \%$ SDS-PAGE Gel (Eurogentec, ID-PA4121-015) in $1 \times$ MOPS buffer at $150 \mathrm{~V}$ for $1 \mathrm{~h}$. The PVDF membrane was activated by $30 \mathrm{~s}$ in methanol, $5 \mathrm{~min}$ in water and $10 \mathrm{~min}$ in $1 \times$ transfer buffer (tris base $0.25 \mathrm{M}$ and glycine 1.9 M). After electrophoresis, proteins were transferred to PVDF membranes in $1 \times$ transfer buffer and $20 \%$ ethanol for $2 \mathrm{~h}$ at $100 \mathrm{~V}$ at $4^{\circ} \mathrm{C}$. Protein $\mathrm{A}$ was blocked by incubation over night at $4^{\circ} \mathrm{C}$ in $1 \times$ TBS, $5 \%$ milk, $0.1 \%$ Tween 20 and $1 / 500$ human serum. The membranes were then incubated

\section{REFERENCES}

Beaume, M., Hernandez, D., Farinelli, L., Deluen, C., Linder, P., Gaspin, C., et al. (2010). Cartography of methicillin-resistant S. aureus transcripts: detection, orientation and temporal expression during growth phase and stress conditions. PLoS ONE 5:e10725. doi: 10.1371/journal.pone.0010725

Bohn, C., Rigoulay, C., and Bouloc, P. (2007). No detectable effect of RNAbinding protein Hfq absence in Staphylococcus aureus. BMC Microbiol. 7:10. doi: 10.1186/1471-2180-7-10

Brantl, S. (2014). Plasmid replication control by antisense RNAs. Microbiol. Spectr. 2, PLAS-0001-2013. doi: 10.1128/microbiolspec.PLAS-0001-2013

Brantl, S. (2015). Antisense-RNA mediated control of plasmid replication - pIP501 revisited. Plasmid 78, 4-16. doi: 10.1016/j.plasmid.2014.07.004 with a primary anti-FLAG antibody (Sigma-Aldrich, \#F3165) or anti-CshA antibody and a secondary antibody Goat anti-mouse fused to HRP (Bio-Rad, \#1706516). RepA-FLAG was revealed using Chemiluminescent Western Blot Detection kit (Thermo Fisher Scientific, \#RPN2232) and the signals were detected using Bio-Rad ChemiDoc MP Imager.

\section{DATA AVAILABILITY STATEMENT}

The original contributions presented in the study are included in the article/Supplementary Material, further inquiries can be directed to the corresponding author/s.

\section{AUTHOR CONTRIBUTIONS}

VG, AL, VK, SH, AJ, CM, and PR performed the experiments. VG, JA, JP, PL, and PR analyzed the data. VG, AJ, PL, and PR wrote the manuscript. PL and PR conceptualized the work. All authors contributed to the article and approved the submitted version.

\section{FUNDING}

This work was supported by grants from the Swiss National Science Foundation (to PL) and by grants from the Ernst et Lucie Schmidheiny Foundation, the Société Académique de Genève, and Axes Thématiques Prioritaires de l'UPS (to PR).

\section{ACKNOWLEDGMENTS}

We would like to thank Patrick Viollier, Jean-Yves Bouet, Leonora Poljak, and Dave Lane for critical reading of the manuscript. pCN36 was kindly provided by the Felden lab.

\section{SUPPLEMENTARY MATERIAL}

The Supplementary Material for this article can be found online at: https://www.frontiersin.org/articles/10.3389/fmicb. 2021.586886/full\#supplementary-material

Brantl, S., and Wagner, E. G. (1996). An unusually long-lived antisense RNA in plasmid copy number control: in vivo RNAs encoded by the streptococcal plasmid pIP501. J. Mol. Biol. 255, 275-288. doi: 10.1006/jmbi.199 6.0023

Bugrysheva, J. V., and Scott, J. R. (2010). The ribonucleases J1 and J2 are essential for growth and have independent roles in mRNA decay in Streptococcus pyogenes. Mol. Microbiol. 75, 731-743. doi: 10.1111/j.1365-2958.2009.07 012.x

Campos-Guillén, J., Bralley, P., Jones, G. H., Bechhofer, D. H., and OlmedoAlvarez, G. (2005). Addition of poly(A) and heteropolymeric 3 ' ends in Bacillus subtilis wild-type and polynucleotide phosphorylase-deficient strains. J. Bacteriol. 187, 4698-4706. doi: 10.1128/JB.187.14.4698-4706. 2005 
Cech, G. M., Pakuła, B., Kamrowska, D., Węgrzyn, G., Arluison, V., and SzalewskaPałasz, A. (2014). Hfq protein deficiency in Escherichia coli affects ColE1-like but not $\lambda$ plasmid DNA replication. Plasmid 73, 10-15. doi: 10.1016/j.plasmid. 2014.04.005

Charpentier, E., Anton, A. I., Barry, P., Alfonso, B., Fang, Y., and Novick, R. P. (2004). Novel cassette-based shuttle vector system for gram-positive bacteria. Appl. Environ. Microbiol. 70, 6076-6085. doi: 10.1128/AEM.70.10.6076-6085. 2004

Corvaglia, A. R., François, P., Hernandez, D., Perron, K., Linder, P., and Schrenzel, J. (2010). A type III-like restriction endonuclease functions as a major barrier to horizontal gene transfer in clinical Staphylococcus aureus strains. Proc. Natl. Acad. Sci. U.S.A. 107, 11954-11958. doi: 10.1073/pnas.10004 89107

del Solar, G., and Espinosa, M. (2000). Plasmid copy number control: an evergrowing story. Mol. Microbiol. 37, 492-500. doi: 10.1046/j.1365-2958.2000. 02005.x

Durand, S., and Condon, C. (2018). RNases and helicases in gram-positive bacteria. Microbiol. Spectr. 6, doi: 10.1128/microbiolspec.RWR-0003-201 [Epub ahead of print].

Durand, S., Tomasini, A., Braun, F., Condon, C., and Romby, P. (2015). sRNA and mRNA turnover in gram-positive bacteria. FEMS Microbiol. Rev. 39, 316-330. doi: 10.1093/femsre/fuv007

Edslev, S. M., Clausen, M.-L., Agner, T., Stegger, M., and Andersen, P. S. (2018). Genomic analysis reveals different mechanisms of fusidic acid resistance in Staphylococcus aureus from Danish atopic dermatitis patients. J. Antimicrob. Chemother. 73, 856-861. doi: 10.1093/jac/dkx481

Figaro, S., Durand, S., Gilet, L., Cayet, N., Sachse, M., and Condon, C. (2013). Bacillus subtilis mutants with knockouts of the genes encoding ribonucleases RNase Y and RNase J1 are viable, with major defects in cell morphology, sporulation, and competence. J. Bacteriol. 195, 2340-2348. doi: 10.1128/JB. 00164- 13

Firth, N., Jensen, S. O., Kwong, S. M., Skurray, R. A., and Ramsay, J. P. (2018). Staphylococcal Plasmids, transposable and integrative elements. Microbiol. Spectr. 6, doi: 10.1128/microbiolspec.GPP3-0030-2018 [Epub ahead of print].

Forsdyke. (1995). A stem-loop "kissing" model for the initiation of recombination and the origin of introns. Available online at: https://www. ncbi.nlm.nih.gov/pubmed/?term=PMID\%3A+7476142 [accessed February 20, 2019].

Giraud, C., Hausmann, S., Lemeille, S., Prados, J., Redder, P., and Linder, P. (2015). The C-terminal region of the RNA helicase CshA is required for the interaction with the degradosome and turnover of bulk RNA in the opportunistic pathogen Staphylococcus aureus. RNA Biol. 12, 658-674. doi: 10.1080/15476286.2015. 1035505

Hausmann, S., Guimarães, V. A., Garcin, D., Baumann, N., Linder, P., and Redder, P. (2017). Both exo- and endo-nucleolytic activities of RNase J1 from Staphylococcus aureus are manganese dependent and active on triphosphorylated 5'-ends. RNA Biol. 14, 1431-1443. doi: 10.1080/15476286. 2017.1300223

Khemici, V., Prados, J., Linder, P., and Redder, P. (2015). Decay-initiating endoribonucleolytic cleavage by RNase Y Is kept under tight control via sequence preference and sub-cellular localisation. PLoS Genet. 11:e1005577. doi: 10.1371/journal.pgen.1005577

Kwong, S. M., and Firth, N. (2015). Structural and sequence requirements for the antisense RNA regulating replication of staphylococcal multiresistance plasmid pSK41. Plasmid 78, 17-25. doi: 10.1016/j.plasmid.2015. 01.002

Kwong, S. M., Lim, R., Lebard, R. J., Skurray, R. A., and Firth, N. (2008). Analysis of the $\mathrm{pSK} 1$ replicon, a prototype from the staphylococcal multiresistance plasmid family. Microbiology (Reading, Engl.) 154, 3084-3094. doi: 10.1099/mic.0.2008/ 017418-0

Kwong, S. M., Skurray, R. A., and Firth, N. (2006). Replication control of staphylococcal multiresistance plasmid pSK41: an antisense RNA mediates dual-level regulation of Rep expression. J. Bacteriol. 188, 4404-4412. doi: 10. 1128/JB.00030-06

Laalami, S., Zig, L., and Putzer, H. (2014). Initiation of mRNA decay in bacteria. Cell. Mol. Life Sci. 71, 1799-1828. doi: 10.1007/s00018-013-1472-4

Lin-Chao, S., and Cohen, S. N. (1991). The rate of processing and degradation of antisense RNAI regulates the replication of ColE1-type plasmids in vivo. Cell 65, 1233-1242. doi: 10.1016/0092-8674(91)90018-t
Linder, P., Lemeille, S., and Redder, P. (2014). Transcriptome-wide analyses of 5' ends in RNase J mutants of a gram-positive pathogen reveal a role in RNA maturation, regulation and degradation. PLoS Genet. 10:e1004207. doi: 10.1371/ journal.pgen.1004207

Liu, M. A., Kwong, S. M., Jensen, S. O., Brzoska, A. J., and Firth, N. (2013). Biology of the staphylococcal conjugative multiresistance plasmid pSK41. Plasmid 70, 42-51. doi: 10.1016/j.plasmid.2013.02.001

Liu, M. A., Kwong, S. M., Pon, C. K., Skurray, R. A., and Firth, N. (2012). Genetic requirements for replication initiation of the staphylococcal multiresistance plasmid pSK41. Microbiology (Reading, Engl.) 158, 1456-1467. doi: 10.1099/ mic.0.057620-0

Lobanovska, M., and Pilla, G. (2017). Penicillin's discovery and antibiotic resistance: lessons for the future? Yale J. Biol. Med. 90, 135-145.

Lowy, F. D. (1998). Staphylococcus aureus infections. N. Engl. J. Med. 339, 520-532. doi: 10.1056/NEJM199808203390806

Mathy, N., Hébert, A., Mervelet, P., Bénard, L., Dorléans, A., Li de la Sierra-Gallay, I., et al. (2010). Bacillus subtilis ribonucleases J1 and J2 form a complex with altered enzyme behaviour. Mol. Microbiol. 75, 489-498. doi: 10.1111/j.13652958.2009.07004.x

Mulcahy, M. E., and McLoughlin, R. M. (2016). Host-bacterial crosstalk determines Staphylococcus aureus nasal colonization. Trends Microbiol. 24, 872-886. doi: 10.1016/j.tim.2016.06.012

Nair, D., Memmi, G., Hernandez, D., Bard, J., Beaume, M., Gill, S., et al. (2011). Whole-genome sequencing of Staphylococcus aureus strain RN4220, a key laboratory strain used in virulence research, identifies mutations that affect not only virulence factors but also the fitness of the strain. J. Bacteriol. 193, 2332-2335. doi: 10.1128/JB.00027-11

Oun, S., Redder, P., Didier, J.-P., François, P., Corvaglia, A.-R., Buttazzoni, E., et al. (2013). The CshA DEAD-box RNA helicase is important for quorum sensing control in Staphylococcus aureus. RNA Biol 10, 157-165. doi: 10.4161/rna.22899

Prados, J., Linder, P., and Redder, P. (2016). TSS-EMOTE, a refined protocol for a more complete and less biased global mapping of transcription start sites in bacterial pathogens. BMC Genomics 17:849. doi: 10.1186/s12864-016-3211-3

Pritchard, R. H., Barth, P. T., and Collins, J. (1969). "Control of DNA synthesis in bacteria," in Proceeding of the Microbial Growth (Cambridge: Cambridge University Press), 263-296.

Raj, R., Nadig, S., Patel, T., and Gopal, B. (2020). Structural and biochemical characteristics of two Staphylococcus epidermidis RNase J paralogs RNase J1 and RNase J2. J. Biol. Chem. 295, 16863-16876. doi: 10.1074/jbc.RA120.014876

Redder, P., and Linder, P. (2012). New range of vectors with a stringent 5fluoroorotic acid-based counterselection system for generating mutants by allelic replacement in Staphylococcus aureus. Appl. Environ. Microbiol. 78, 3846-3854. doi: 10.1128/AEM.00202-12

Sambrook, J. F., and Russel, D. W. (2001). Molecular Cloning: A Laboratory Manual. 3rd Edn, Cold Spring Harbor Laboratory Press.

Saramago, M., Bárria, C., Arraiano, C. M., and Domingues, S. (2015). Ribonucleases, antisense RNAs and the control of bacterial plasmids. Plasmid 78, 26-36. doi: 10.1016/j.plasmid.2014.09.003

Shokeen, S., Greenfield, T. J., Ehli, E. A., Rasmussen, J., Perrault, B. E., and Weaver, K. E. (2009). An intramolecular upstream helix ensures the stability of a toxin-encoding RNA in Enterococcus faecalis. J. Bacteriol. 191, 1528-1536. doi: 10.1128/JB.01316-08

Söderbom, F., Binnie, U., Masters, M., and Wagner, E. G. (1997). Regulation of plasmid R1 replication: PcnB and RNase E expedite the decay of the antisense RNA. Cop. A. Mol. Microbiol. 26, 493-504. doi: 10.1046/j.1365-2958.1997. 5871953.x

Somerville, G. A., Beres, S. B., Fitzgerald, J. R., DeLeo, F. R., Cole, R. L., Hoff, J. S., et al. (2002). In vitro serial passage of Staphylococcus aureus: changes in physiology, virulence factor production, and agr nucleotide sequence. J. Bacteriol. 184, 1430-1437. doi: 10.1128/jb.184.5.1430-1437.2002

Srouji, J. R., Xu, A., Park, A., Kirsch, J. F., and Brenner, S. E. (2017). The evolution of function within the Nudix homology clan. Proteins 85, 775-811. doi: 10.1002/ prot. 25223

Tomizawa, J. (1984). Control of ColE1 plasmid replication: the process of binding of RNA I to the primer transcript. Cell 38, 861-870. doi: 10.1016/0092-8674(84) 90281-2

Wagner, E. G., and Brantl, S. (1998). Kissing and RNA stability in antisense control of plasmid replication. Trends Biochem. Sci. 23, 451-454. doi: 10.1016/s09680004(98)01322-x 
Weaver, K. E., Kwong, S. M., Firth, N., and Francia, M. V. (2009). The RepA_N replicons of Gram-positive bacteria: a family of broadly distributed but narrow host range plasmids. Plasmid 61, 94-109. doi: 10.1016/j.plasmid.2008. 11.004

Xu, F., Lin-Chao, S., and Cohen, S. N. (1993). The Escherichia coli pcnB gene promotes adenylylation of antisense RNAI of ColE1-type plasmids in vivo and degradation of RNAI decay intermediates. Proc. Natl. Acad. Sci. U.S.A. 90, 6756-6760. doi: 10.1073/pnas.90.14.6756

Zuker, M. (2003). Mfold web server for nucleic acid folding and hybridization prediction. Nucleic Acids Res. 31, 3406-3415. doi: 10.1093/ nar/gkg595
Conflict of Interest: The authors declare that the research was conducted in the absence of any commercial or financial relationships that could be construed as a potential conflict of interest.

Copyright $\odot 2021$ Guimarães, Le Scornet, Khemici, Hausmann, Armitano, Prados, Jousselin, Manzano, Linder and Redder. This is an open-access article distributed under the terms of the Creative Commons Attribution License (CC BY). The use, distribution or reproduction in other forums is permitted, provided the original author(s) and the copyright owner(s) are credited and that the original publication in this journal is cited, in accordance with accepted academic practice. No use, distribution or reproduction is permitted which does not comply with these terms. 